\title{
Etnia y nación en la lucha por el reconocimiento. Los mapuches en la sociedad chilena
}

Rolf Foerster G. ${ }^{2}$ Y Jorge IVÁn Vergara ${ }^{3}$

\begin{abstract}
"Si hubiera podido escoger el lugar de mi nacimiento, habría escogido...un Estado ...en el que el dulce hábito de verse y conocerse hiciera del amor a la patria el amor por los ciudadanos antes que el amor por la tierra" (Rousseau 1754:
\end{abstract}

180-181)

\section{RESUMEN}

Los conflictos entre mapuches, Estado y sociedad chilena se analizan desde la perspectiva de una "lucha por el reconocimiento", o sea, como una disputa por el sentido y carácter de la relación de los mapuches con la sociedad chilena. Se plantea la tensión entre diversas exigencias de reconocimiento por parte de los indígenas (campesina, étnica y etnonacional) y las corrrespondientes políticas de reconocimiento del Estado y la sociedad chilena. Luego de exponer el desarrollo del debate teórico sobre las políticas de reconocimiento y el multiculturalismo, se analiza el caso mapuche en Chile. considerando la perspectiva indígena, de la élite chilena a través de El Mercurio y del Gobierno. Se concluye proponiendo algunas vías de salida a la discusión teórica (y política) sobre la compleja relación etnia-nación.

\footnotetext{
ABSTRACT

The conflicts between the mapuche people, the State

1 Una primera versión más sintética de este artículo fue presentada al XII Congreso Internacional: Derecho consuetudinario y pluralismo legal: Desafíos en el tercer milenio, Arica, 13 al 17 de marzo de 2000 , e incluida en las Actas de dicho congreso (Foerster y Vergara 2000: 191-206). Este trabajo se enmarca dentro del proyecto de investigación FONDECYT, ¿Demanda étnica o demanda etnonacional mapuche? (Proyecto $\mathrm{N}^{\circ} 100024$, período 2000-2001)

2 Universidad de Chile, Santiago, E-mail: rfoerste@uchile.cl

3 Universidad Arturo Prat, Iquique, E-mail: jovergar@cec.unap.cl
}

and society are analysed from the "struggle for recognition" perspective, i.e. as a dispute for the sense and character of the relationship between mapuches and chilean society. It is here presented the tension between the various demands of recognition set forth by the aborigines (peasant, ethnic, and ethno-national), the corresponding State policies of recognition, and the chilean society. After referring to the development of the theoretical debate on recognition policies and multiculturalism, the chilean mapuche case is analysed, considering the proposals made by the indigenous people, the Chilean élites -as shown by "El Mercurio" daily, and the Government. The essay concludes with some propositions aiming at the solution of the theoretical (and political) discussion of the complex ethnonation relationship.

\section{Introducción}

La "cuestión mapuche" ha cobrado en el Chile actual una creciente y paradójica importancia. Creciente, pues ha concitado cada vez mayor atención por parte de la opinión pública, los medios de comunicación, el mundo político y la sociedad civil. Paradójica, porque no obstante los logros alcanzados con la promulgación de la ley indígena y la mayor sensibilidad hacia la sociedad mapuche y sus demandas, no ha habido una transformación sustantiva de los modos de relacionarse con ella de parte del Estado, ni de las empresas, ni menos aún de la siempre influyente élite dominante y su voce- 
ro. El Mercurio. ${ }^{4}$ Asimismo, se ha producido un significativo aumento en el número e intensidad de los "conflictos étnicos", sobre cuya resolución parece no haber acuerdo entre las instancias involucradas.

Nos interesa dar cuenta de este desencuentro, por lo menos parcial, que contrasta fuertemente con el consenso que se generó hace algunos años cuando se creó la Comisión Especial de Pueblos Indígenas (CEPI), y luego, cuando se promulgó la ley indígena, y el optimismo que despertó entonces dentro de la intelectualidad indigenista $y$, aunque con reservas, en el movimiento indígena.

Recordemos que el entonces Presidente Patricio Aylwin, al comienzo de la transición, afirmaba que "mi gobierno quiere establecer una relación diferente con los pueblos indígenas de Chile", "raíces de nuestra nación" (Aylwin 1991: 4). O también su declaración sobre "el reconocimiento de los Pueblos Indígenas como parte de la diversidad de la sociedad chilena" (Aylwin 1990: 44); así como el entusiasmo del director de la CEPI y más importante intelectual indigenista del país, José Bengoa, para quien la creación de la Comisión mostraba "un nuevo tipo de relacionamiento entre el Estado, la sociedad y los Pueblos Indígenas" (Bengoa 1990: 48). ${ }^{6}$

Una década después, estas declaraciones bien intencionadas y esperanzadas parecen muy lejanas frente a la realidad de un conflicto étnico que se ha ido incrementando desde hace varios años. Diversos análisis se han ocupado de seguir cronológicamente los acontecimientos y acciones que han llevado a esta situación. ${ }^{7}$ Aquí, en cambio, nos interesa proponer una interpretación más am-

4 El ex director de CONADI, Domingo Namuncura, refleja bastante optimismo cuando afirma que "(los) editoriales conservadores...son notas que navegan contra la corriente de un proceso nuevo y emergente en la ciudadanía, que deriva de la conciencia y del respeto hacia nuestros ecosistemas y nuestras culturas originarias" (Namuncura 1999: 297). Sin embargo, por muy minoritaria que pueda ser, la de El Mercurio es la voz de una "minoría consistente" y "el poder de una minoría radica en su capacidad de definir las condiciones sociales de manera tal que sus normas explícitas aparecen acorde con la realidad, o sea que las condiciones sociales hacen aparecer sus normas como buenas y racionales" (Lechner 1984: 57).

5 Para Aylwin. "Un país moderno debe reconocer las diversas culturas que hay en su interior. La existencia de diversas culturas enriquece a la sociedad, a la Nación, a la cultura nacional. La nueva ley debe salvaguardar a estos pueblos, que son los pueblos primigenios de Chile" (1990: 44). plia, que considere un elemento hasta ahora no desarrollado conceptualmente en los estudios e investigaciones sobre el tema: las demandas y políticas de reconocimiento. ${ }^{8}$ Para ello nos referiremos a algunos elementos centrales del debate teórico sobre el problema del reconocimiento y las identidades culturales y étnicas. Creemos que esta discusión puede ser aportadora en la comprensión del caso mapuche. ${ }^{9}$

Desde esta perspectiva, interpretamos las movilizaciones, organizaciones y reivindicaciones mapuches como una forma de lucha por el reconocimiento, que ha tenido históricamente dos grandes dimensiones: campesina (demandas por créditos agrícolas, mejoramiento de infraestructura, etc.) y étnica (demandas por el respeto a la identidad mapuche, educación intercultural bilingüe y discriminación legal positiva, entre otras). Nuestra hipótesis es que en los últimos años ha emergido una tercera dimensión, que incorpora las dos anteriores y les da un sentido nuevo y diferente: una demanda por el reconocimiento como pueblo-nación, que denominaremos etnonacional. ${ }^{10}$

A su vez, desde la recuperación de la democracia, el Estado chileno puso en práctica una política de reconocimiento que ha permitido satisfacer parcialmente las demandas de tipo campesina y étnica, mientras la demanda etnonacional no ha encontrado eco en ningún sector político o social significativo de la sociedad chilena. Por el contrario, con la

6 Y añadía: "el Gobierno está dando la señal de... [no] querer continuar con un tipo de política que se ha desarrollado en el pasado, es decir, con una política integracionista, asimiladora. Por el contrario, quiere realizar una política de reconocimiento, de respeto, de valorización de la cultura, de valorización de la autonomía de estos pueblos...Insisto en que es un signo... nada más que eso, pero dado lo que ha ocurrido en los últimos años con los pueblos indígenas, yo creo que un signo es ya algo importante" (1990: 48).

7 Veáse, por ejemplo: Aylwin (1998). Un notable testimonio sobre el gobiemo y las políticas indígenas en tomo al caso Ralco se encuentra en el libro de Namuncura (1999) sobre su período como director de CONADI.

8 Bengoa (2000: 126-128) es el único estudioso del mundo mapuche que no sólo habla explícitamente del problema del reconocimiento sino que inclusive lo define como una "cuestión fundamental". Sin embargo, no aborda su dimensión conceptual ni la variedad de formas de reconocimiento. Básicamente, la categoría se utiliza en forma descriptiva para caracterizar la "demanda indígena", cuyo contenido fundamental sería la exigencia que "el Estado y la sociedad los reconozca como indígenas". 
emergencia o reconstitución de un movimiento mapuche autónomo y con fuerte capacidad de movilización, ha ido desarrollándose un conflicto que ha tendido a polarizarse en dos frentes. Por un lado, en el movimiento etnonacional mapuche, que cuestiona de manera radical la política estatal y pugna por una autonomía político-territorial. Por otro, en los sectores conservadores, donde se incluyen tanto la derecha política como el empresariado y los medios de comunicación que los representan, para los cuales la política seguida desde 1990 ó 1993 ha significado un estímulo para la radicalización del movimiento mapuche y conlleva una seria amenaza al orden político e institucional vigente.

En cuanto al Gobierno, éste se ha visto limitado en su capacidad de contener el conflicto, ya sea satisfaciendo en mayor grado las demandas mapuches (sobre todo, las demandas étnica y etnonacional), buscando nuevas formas de negociación y diálogo (como las mesas de diálogo) o aplicando una política represiva y de integración forzosa, como propugna el sector conservador. Parte de esta debilidad es causada, a su vez, por la pérdida de legitimidad y poder del movimiento mapuche que participa de la CONADI, instancia que, siendo originalmente mediadora, se ha ido transformando en una agencia más de Gobierno. Con ello ha perdido en buena medida el carácter de ser también una representación del movimiento indígena, como pretendió serlo en sus inicios. $^{11}$

9 Metodológicamente, se busca superar el empirismo descriptivo que domina muchos análisis de la situación indígena en Chile, sin caer por ello en un esquematismo teórico, en la apiicación de categorías teóricas sin mediación para el caso en estudio. Sigue siendo válido el diagnóstico hecho hace dos décadas por Lechner respecto a las ciencias sociales latinoamericanas: "Pareciera existir un déficit teórico: los estudios no logran sobrepasar la descripción histórica hacia una conceptualización del proceso social como totalidad. La investigación empírica no es acompañada de una teorización; no se logra establecer una mediación entre la forma concreta en que se presenta la sociedad y la abstracción lógica que muestre la racionalidad subyacente" (Lechner 1980: 231).

10 Para Connor (1994: X) nacionalismo y etnonacionalismo son sinónimos, dado que la nación "connota un grupo de personas que creen estar relacionadas ancestralmente". Sin embargo, nosotros usaremos la expresión con un sentido más específico, para connotar un nacionalismo de origen étnico, diferenciable de otras formas de nacionalismo, como el del movimiento de las "Ligas Patrióticas" surgido en el norte de Chile a principios de siglo (González et al. 1993, González 1999). Sobre el etnonacionalismo mapuche se hizo una primera aproximación en Foerster (1999).
Asimismo, la política gubernamental se ha reorientado a satisfacer las demandas de tipo campesina, dejando las reivindicaciones étnicas en un segundo plano, un retroceso parcial hacia la política integracionista y campesinista que parecía definitivamente abandonada en 1990 ó 1993.12

Mostrar cómo se manifiesta hoy en día la ruptura de visiones y de consensos en torno a la política del reconocimiento étnico es el objeto de este artículo. Comenzaremos con una discusión del enfoque teórico del trabajo y los aspectos normativos implicados en la discusión filosófica sobre el reconocimiento étnico-cultural, basándonos principalmente en Taylor y Habermas, y haciendo al final algunas referencias al debate latinoamericano. Justificamos este énfasis en la poca relevancia que se le da generalmente a las cuestiones teóricas (y filosóficas) en las ciencias sociales latinoamericanas. Intentaremos por lo menos comparar algunos planteamientos cen-

11 Como bien dice Cerroni (1969: 21): "precisamente la admisión de la necesidad de una mediación deja entrever la permanencia de los dos términos, uno de los cuales, la sociedad civil (leáse aquí los pueblos indígenas. R.F. y J.I.V), se halla mediado por el Estado". La crisis actual ha cuestionado esta capacidad de mediación del Estado, tanto respecto de las demandas indígenas, como respecto de los grandes intereses económicos del país. Dejamos de lado aquí el problema más general de si esta crisis es temporal o constituye un cambio más permanente o incluso definitivo respecto al rol mediador del Estado, sobre todo entre sociedad y mercado. Lechner ha tratado el problema en diversos trabajos recientes, pero ha dejado la respuesta abierta. Por un lado, recoge la visión sistémica de Willke, donde el Estado es parte de un subsistema específico, el subsistema político, que tiene a lo sumo una "función coordinadora", y por tanto, ha perdido su centralidad respecto a los demás subsistemas sociales. Por otra parte, sostiene que el Estado continúa teniendo dicho rol de "articulación entre lo económico, lo social, lo político y lo cultural" (Lechner, 1991: 58), pero que éste "se encuentra en entredicho no sólo en América Latina” (Lechner 1997: 9).

12 Decimos esto sin hacer un juicio de valor. "Retroceso" se entiende aquí simplemente como una vuelta --insistimos, parcial-- a la política indígena vigente hasta el retorno de la democracia. Esto se refiere sobre todo a la acción del poder ejecutivo, CONADI y MIDEPLAN, y a los temas más ligados a los conflictos, como tierras y megaproyectos. No es válido necesariamente para las políticas ministeriales y municipales de salud, educación y vivienda, cuyo análisis requeriría otra aproximación metodológica. Probablemente, en este ámbito de acción del Estado no se ha producido un cambio tan importante respecto de las políticas tradicionales que se aplican en los sectores rurales o en las ciudades, donde además no se diferencia en muchos casos entre campesinos, pobladores y mapuches. 
trales de ambos debates. ${ }^{13}$ No siendo nuestra formación filosófica, debemos advertir del carácter necesariamente preliminar de nuestro trabajo, sin poder desarrollar en profundidad cada uno de los planteamientos expuestos. Asimismo, nos veremos obligados a referimos a cuestiones más amplias que las relativas al caso en estudio. El lector atento podrá percibir los vínculos con éste, sobre los que volveremos al final, en las conclusiones.

A continuación, presentaremos un análisis esquemático de las demandas indígenas actuales y su recepción por el Gobierno y analizaremos más a fondo la visión de la élite dominante en Chile, tal cual la representa El Mercurio. Nuestra hipótesis es que este sector asume una concepción de la nación como nación-pueblo, o sea, como una entidad prepolítica, integrada por descendencia, tradición compartida y lengua común, y no la definición republicana de la nación de ciudadanos. ${ }^{14}$ Sin embargo, también ha incorporado la idea del Estado como formador de la nación, lo que no obsta para que ella siga siendo pensada en base a una idea de rasgos comunes étnico-culturales, como una unidad homógenea y sustantiva. Esto tiene, por necesidad, que excluir las diferencias culturales o condenarlas como una forma de división y desintegración nacional.

En consecuencia, y como veremos en detalle más adelante, desde esta posición se plantea un cuestionamiento radical a la ley indigena y a la política indígena de reconocimiento étnico de los gobiernos de la Concertación. Este rechazo explica, en parte, el giro etno-nacional de un sector significativo del movimiento y la intelectualidad mapuche, lo que definiría un nuevo escenario político.

Por ende, y si nuestro análisis es correcto, la disputa por el reconocimiento ha perdido, al menos momentáneamente, y si se consideran las posiciones extremas, todo marco común, todo horizonte compartido. Veremos los argumentos centrales de los

13 Esto nos parece mejor que simplemente ignorar dichas discusiones en nombre de la peculiaridad latinoamericana o trasladar a nuestra realidad ciertos conceptos teóricos de algún autor o corriente europea o norteamericana. Como señala Lechner, América Latina "requiere y a la vez refuta los conceptos elaborados en las sociedades capitalistas desarrolladas" (1985: 24-25).

14 La distinción entre estos dos conceptos está desarrollada por Habermas en sucesivos trabajos (Habermas 1992, 1996a y 1996b: 128-153). De este último texto, el más amplio sobre el tema, hay traducción al español (Habermas 1999: 81-105). mapuches, el Gobierno y la opinión pública conservadora en este último período de tensiones y conflictos de distinta índole. ${ }^{15}$

\section{La lucha por el reconocimiento en la discusión teórica del Primer Mundo y América Latina}

En lo fundamental, no nos proponemos aquí aportar nuevos antecedentes sobre los sucesos que han llevado a la virtual ruptura entre el Estado chileno y la mayoría de las organizaciones mapuches. Estos hechos son ya bien conocidos por todos quienes se han preocupado del tema, y han trascendido a la opinión pública a través de numerosas notas periodísticas, declaraciones públicas, marchas y concentraciones. ${ }^{16}$ Nos referiremos a ellos sólo en cuanto sea necesario para apoyar los argumentos expuestos.

Más bien nos interesa contribuir a identificar lo que podría denominarse la gramática del conflicto étnico, desde una perspectiva que nos parece puede enriquecer el debate en curso sobre las relaciones Estado-pueblos indígenas: las políticas de reconocimiento. Bajo este concepto, ampliamente utilizado a partir del trabajo del filósofo canadiense Charles Taylor $^{17}$, pueden entenderse mejor fenómenos que hasta ahora han sido conceptualizados de manera muy heterógenea y, en ciertos casos, inapropiada.

Nos interesa examinar las políticas y demandas de reconocimiento en el caso mapuche, y entender el conflicto generado en torno a su definición y orientación, lo que, siguiendo la intepretación de Hegel

15 Desde los sucesos de Lumaco en 1997, la crisis de Ralco y la salida de Huenchulaf y Namuncura como directores de CONADI en abril de 1997 y agosto de 1998 , respectivamente; $\mathrm{y}$, finalmente, los casos de Malleco y Traiguén. Un análisis de conjunto de estos conflictos, asi como de sus diferencias, puede verse en: Aylwin (2000), Naguil (1999) y Foerster y Lavanchy (1999). Debe consultarse también el interesante trabajo de Mallon (1999). No obstante su cuidadosa argumentación histórica, en nuestra opinión Mallon se equivoca al poner el conflicto de Ralco en un mismo plano con los conflictos territoriales como Lumaco o Traiguén. De aquí la necesidad de diferenciar tipos de conflictos (por ejemplo, Naguil 1999) y también reconocer los elementos nuevos, sobre todo aquellos ligados a los actuales procesos de modernización, que no se explican por la larga duración histórica. 16 Véase los trabajos citados en la nota anterior, y los estudios de Javier Lavanchy (1999a y 1999b) y José Mariman (1998).

17 Véase: Taylor (1992 y 1993). También es de interés la entrevista a Taylor realizada por la revista española Debats (Taylor 1994). 
por Honneth, denominaremos "lucha por el reconocimiento" (Honneth 1989 y 1992). De acuerdo a Honneth, Hegel habría contrapuesto a la visión de Maquiavelo y Hobbes de la "lucha social" por la sobrevivencia, la tesis que las confrontaciones entre los sujetos tienen una dimensión moral, suponen un potencial para un proceso de formación/ aprendizaje (Bildungsproze 3 ), que conduce gradualmente a la formación de perspectivas más amplias de reconocimiento mutuo (Honneth 1989: 570).

Teóricamente, este podría llegar a ser el caso de los mapuches si se satisfacieran, por parte de todos los involucrados, condiciones para un diálogo efectivo y no una negociación de intereses; de búsqueda de entendimiento bajo el reconocimiento de la autonomía e igualdad de cada uno de ellos. Por el contrario, lo que prima actualmente se acerca más a la concepción político-realista de una lucha de poder, donde la existencia de un movimiento indígena autónomo es considerado como amenaza al orden vigente, y esto no sólo por la derecha y El Mercurio; también por políticos y autoridades de la actual coalición de gobierno. Contribuye a lo anterior una visión de la democracia que la restringe a ser un método político ajeno en gran medida a los problemas de desigualdad social, económica y étnica, así como a las violaciones a los derechos humanos durante las dictaduras militares precedentes (Hinkelammert 1987a). Violaciones que, en el caso de los pueblos indígenas, han hecho (sensu Benjamín ca. 1942: 53) del "estado de excepción" la regla.

Sin embargo, aún así y sin que esto sea siempre percibido por los involucrados, la lucha por el reconocimiento no es únicamente un conflicto por el poder, el control territorial o la distribución de recursos económicos, sino que es también una disputa por el sentido y amplitud que debe tener el reconocimiento. ${ }^{18}$ De aquí la importancia que le atribuímos a los discursos políticos. Estos son, en parte, verdaderos actos de habla políticos. Poseen una materialidad y una intencionalidad, pero no se agotan en ellas, sino que comprenden también argumentos de

18 "La 'política' es a su vez objeto de la lucha política... es siempre una lucha por definir lo que es la política" (Lechner 1984: 13). Por ende, no se reduce a la acción instrumental --o estratégica, podría agregarse--, tiene también "una dimensión normativa y simbólica, regulando y representado las relaciones sociales" (Lechner 1984: 46).

19 No se trata entonces de meros "discursos de fundamentación", sino también de "discursos de aplicación", pretensiones nor- tipo ético y moral: en este caso, definen cómo debe entenderse y practicarse la relación etnias-Estado, qué debe aceptarse como pretensiones legítimas de éstas y qué no. ${ }^{19}$

¿Qué se entiende entonces por 'lucha por el reconocimiento' y cuál es su importancia en la formación de las identidades culturales? Para responder a esta cuestión será necesario detenernos con cierto detalle en algunas cuestiones de teoría social. Afortunadamente, el trabajo de Taylor (1993) contiene una exposición muy lograda al respecto. De acuerdo a él (1993), el problema del reconocimiento emergió con la modernidad. El desplome de las jerarquías sociales basadas en el honor llevó el reemplazo de esta noción por el moderno concepto de dignidad, lo que supuso la idea de un reconocimiento igualitario en el marco de una cultura democrática. A esto se sumó, ya en el siglo XVIII, la concepción de una identidad individualizada, independiente de las adscripciones sociales; o sea, un ideal de autenticidad. La autenticidad consistiría en una relación moral del sujeto consigo mismo.

Rousseau habría sido quien más contribuyó a la formulación filosófica de esta nueva visión. Su llamado a una salvación moral del hombre a través de "la recuperación de un auténtico contacto moral con nosotros mismos" (Taylor 1993: 49), sirvió de base para una crítica profunda de la sociedad de su época y de los modos de socialización vigentes en ella. ${ }^{20}$ Para Rousseau, hay que sustituir una sociabilidad basada en el egoísmo y la apariencia, propia de la cultura del absolutismo, por una sociabilidad basada en la comunidad y en una democracia participativa, acorde con el estado natural del hombre, pero que significa, dialécticamente, también su superación. ${ }^{21}$

mativas que formulan una exigencia de validez con fuerza obligatoria. Tomamos estas distinciones de Habermas (1988a: 74 y siguientes).

20 "Con qué claridad habría hecho ver todas las contradicciones del sistema social. con qué fuerza habría expuesto todos los abusos de nuestras instituciones. con qué sencillez habría demostrado que el hombre es naturalmente bueno y que sólo por las instituciones se vuelven malvados los hombres" (Rousseau, citado por Armiño 1980: II).

21 Nos basamos aquí en la excelente exposición de Colleti (1969). Véase también: Armiño (1980) y Fetscher (1983). Para Fetscher, "Quien defienda el derecho de los pequeños grupos étnicos a su identidad, puede encontrar argumentos en Rousseau" (1983:27). 
Herder, cuya filosofía de la historia recibió la influencia de la crítica rousseauniana al progreso, amplió la concepción de la autenticidad con la idea que "cada uno de nosotros tiene un modo original de ser humano: cada persona tiene su propia medida" (Taylor 1993: 49). ${ }^{22}$ Ser fiel a mí mismo emerge como un imperativo que me permite descubrir mi originalidad. Y esto vale tanto para los individuos como para los pueblos: "Un Volk debe ser fiel a sí mismo, es decir a su propia cultura" (Taylor 1993: 51). ${ }^{23}$ Para los germanistas y filólogos alemanes del siglo XIX, este imperativo adquirió su traducción política en el proyecto de conformación de la unidad nacional alemana sobre la base de la unidad cultural, expresada fundamentalmente en la lengua, cuya pureza debía ser rescatada (Habermas, 1998: 18-26).

La identidad individual surge en una relación dialógica. El descubrimiento de la propia identidad emerge del diálogo abierto e interno con los demás. "Por ello, el desarrollo de un ideal de autenticidad que se genera internamente atribuye una nueva importancia al reconocimiento. Mi propia identidad depende, en forma crucial, de mis relaciones dialógicas con los demás" (Taylor 1993: 55); "nos definimos siempre dialogando, siempre por medio del intercambio con los otros" (Taylor 1992: 136). El reconocimiento ya no puede entonces descansar en "una identidad socialmente derivada". Debe ser ganado en el vínculo con los otros. Aquí radica, según Taylor, la novedad de la época moderna: "la ponderación de las condiciones en que el intento de ser reconocido puede fracasar" (Taylor 1993: 56). Y emerge también el problema del no reconocimiento:

\section{"Nuestra identidad --dice Taylor-- se moldea en parte por el reconocimiento o por la falta de éste; a menudo también por el falso reconocimiento de otros, y así, un individuo o un grupo de personas puede sufrir un verdadero daño, una auténtica de- formación si la gente o la sociedad que lo rodean le}

22 Sobre la influencia de Rousseau sobre Herder y los aspectos nuevos que éste incorporó, véase: Meinecke (1936, cap. IX: 305-378).

23 Meinecke (1936: 318) describe así el paso de Herder de una visión del sujeto individual a una visión colectiva, del pueblo: "Herder comenzó... a comparar la vida con la historia, sólo obtuvo, al principio, una semejanza entre el niño y el hombre natural, entendido un poco a la manera de Rousseau...pero, entonces, la imagen profundamente conmovedora de la vida del pueblo letón y de la poesía popular letona, lo condujo al muestran, como reflejo, un cuadro limitativo, o degradante o despreciable de símismo. El falso reconocimiento puede causar daño, puede ser una forma de opresión que aprisione a alguien en un modo de ser falso, deformado o reducido" (1993: 43-44).

Este es claramente el caso de los mapuches en Chile, cuya imagen desvalorizada en la sociedad chilena condiciona también el surgimiento de una autoimagen negativa en muchos miembros de este pueblo (Stuchlik 1974 y 1985). ${ }^{24}$ Lo que tiene a su vez como consecuencia que no se sientan formando parte de un "proyecto compartido con los miembros de la mayoría" (Taylor 1992: 137). ${ }^{25}$ El reconocimiento es, pues, de naturaleza social, aunque afecta a las personas individuales y a los grupos. $Y$ esto ocurre no sólo en el ámbito de las relaciones privadas sino también en el seno del espacio público, que adquiere una creciente importancia como objeto de examen, reflexión, crítica y reforma. ${ }^{26}$ Emerge así una política universalista de reconocimiento igualitario y la consiguiente aceptación universal del "principio de ciudadanía igualitaria" (Taylor 1993: 60). En él se comprenden los llamados derechos civiles y políticos, y, según las interpretaciones, los derechos económicos. Se trata de un universalismo igualitario, que tiene como eje la

más comprensivo concepto del pueblo, que lleva más allá de Rousseau, todavía de un atomismo iusnaturalista".

24 Sobre la visión de los intelectuales mapuches respecto a este tema, véase: Kotov y Vergara (1997), que incluye básicamente trabajos de las décadas del setenta y el ochenta. Falta una indagación sobre la interpretación de los intelectuales mapuches actuales.

25 La cita completa es como sigue: "una etnia minoritaria no se siente verdaderamente reconocida por la mayoría con la cual debe compartir una misma entidad política. En lo sucesivo es imposible, cuando menos díficil, para las personas de esa minoría sentirse parte verdaderamente activa de un proyecto compartido con los miembros de esa mayoría. Por el contrario, se sienten subsumidas en un proyecto que les es extraño porque no se sienten verdaderamente reconocidas" (Taylor 1992: 137). Nos parece que, si bien esto refleja la situación actual, no tiene necesariamente plena vigencia respecto a períodos anteriores, en los cuales los mapuches, estando claramente en esta condición de minoría étnica bien descrita por Taylor, se identificaron al menos parcialmente con la nación chilena.

26 Según Koselleck (1959:41-48 y 1965:93-108). Locke, "padre espiritual de la ilustración burguesa", fue el primero de los pensadores ilustrados en plantear la importancia del espacio público en la formación de la moralidad social. Koselleck muestra las diferencias políticas que tuvo este discurso respecto de la Ilustración francesa. Para una reflexión teórica sobre este problema en el Chile republicano, véase: García (1999). 
igualdad ante la ley y el derecho a no ser objeto de trato arbitrario, abuso o violencia de parte de terceros o de los mismos Estados que deben garantizar los derechos individuales. ${ }^{27}$

Pero la política de reconocimiento igualitario tiene otro componente, que contrasta con el anterior: "la política de la diferencia", o sea, la exigencia de un reconocimiento de "la identidad única de este individuo o grupo, el hecho que es distinto de todos los demás" (Taylor 1993: 61). Esta forma de reconocimiento reivindica la especificidad y plantea inclusive una discriminación a la inversa, lo que generalmente conocemos como discriminación positiva, con el objeto de revertir una situación anterior y extendida de discriminación negativa. Puede ser vista como una forma de nivelar la situación de los distintos individuos hasta colocarlos a todos en una misma posición, donde no haya discriminación (Taylor 1993: 63). Lo que se valora es un "potencial humano universal", "el potencial de moldear y definir nuestra propia identidad, como individuos y como cultura" (Taylor 1993: 65). Y a esto se ha agregado en los últimos años, la exigencia de "acordar igual respeto a las culturas que de hecho han evolucionado" (Taylor 1993: 66).

La declaración atribuida a o dicha por Bellow: "Cuando los zulúes produzcan un Tolstoi, entonces los leeremos", puede considerarse una doble afrenta a este pueblo. Primero, porque rechaza los valores de la cultura zulú, que pueden ser diferentes pero no inferiores a los de la cultura europea; segundo, porque excluye en principio la posibilidad que los zulúes puedan desarrollar expresiones culturales a la altura de las expresiones culturales europeas. Y en este segundo sentido, la afirmación "refleja el rechazo al principio de la igualdad humana" (Taylor 1993: 66). Sólo que no se trata de una negación de la igualdad humana de los zulúes en cuanto seres humanos, como podría haber ocurrido en la época del colonialismo o la esclavitud, sino del rechazo de la cultura zulú en cuanto a su valor en compara-

27 Aquí también debe considerarse a Locke como un precursor. Locke fue el primero en plantear la idea de un estado de derecho, en el cual las leyes tiene el carácter de universales y regulan no sólo las relaciones entre los ciudadanos sino también entre éstos y el Estado, lo que no aparece ni en Maquiavelo ni en Hobbes. Locke distingue entre la ley, universal, y la decisión administrativa, que es particular (Locke 1690). En Locke aparece asi el principio de la soberanía de la ley, que después va a desarrollarse en Montesquieu y en el constitucionalismo norteamericano. ción con otras culturas (en este caso, a la cultura europea occidental). Por supuesto, que a los individuos miembros de esta cultura también les es negada, en esta forma, su capacidad de un desarrollo cultural comparable a la de los individuos miembros de otras culturas. Pero lo central está en el primer aspecto, el de la desigualdad cultural.

Sin embargo, la afirmación del principio de la igualdad cultural ha ido recientemente más lejos que una crítica a planteamientos eurocéntricos como el anterior. Para algunos, la misma política de la dignidad igualitaria puede ser considerada como la expresión, "el reflejo de una cultura hegemónica" (Taylor 1993: 67). Supone que existen ciertos principios universales "ciegos a la diferencia". Pero esta ceguera sólo se da respecto de las culturas distintas a la cultura que se impone a través de principios particulares, no verdaderamente universales. El liberalismo, que sostiene teóricamente esta posición, sería también expresión política de ciertas culturas, "totalmente incompatibles" con otras (Taylor 1993: 92).

Para Taylor, esta crítica nos revela una insuficiencia intrínseca del planteamiento de la dignidad igualitaria, que encontramos ya en Rousseau. La defensa rousseauniana del igualitarismo, que recoge la crítica estoica del orgullo pero reconoce la importancia de la estima señalada por la ética del honor, supone una "densa unidad de propósito que parece incompatible con cualquier diferenciación. Para Rousseau, la clave para un estado libre parece ser la rigurosa exclusión de toda diferenciación de roles" (Taylor 1993: 77). El igualitarismo parece entonces requerir una política homogenizadora. Taylor examina este problema a la luz del caso de Quebec.

Una primera posición es la representada por liberales como Dworkin o Rawls, para quienes en una sociedad liberal no puede adoptarse "ninguna posición sustantiva particular acerca de los fines de la vida". La sociedad está unida por un "compromiso procesal" de "tratar a las personas con igual respeto" (Taylor 1993: 85). Una sociedad liberal es, por tanto, "neutral ante la vida buena" y se limita a garantizar un trato imparcial de los ciudadanos entre sí y por el Estado. Esta versión del liberalismo sería insensible a las diferencias, en la medida que se requiere una aplicación uniforme de las reglas que definen los derechos individuales y se desconfía de las metas colectivas (Taylor 1993: 91). La sociedad 
no puede considerar la integridad de formas de vida, como las de grupos étnicos o minorías, como un bien jurídico a proteger.

Sin embargo, existe otra interpretación del liberalismo $^{28}$, aquella que sostienen los partidarios de la defensa de la cultura francófona en Quebec. Ellos consideran aceptable la organización de la sociedad en torno a una vida buena y reconocer los derechos colectivos de la minoría francófona canadiense, siempre y cuando esto no signifique el desprecio y el rechazo a los derechos individuales de quienes no comparten esta visión. Se puede ser liberal, reconocer derechos individuales, y respetar al mismo tiempo la diversidad de ciertas formas de vida, como las de la minoría francesa canadiense (Taylor 1993: 88-89). Taylor da a entender que esta posición es más acorde que la primera con la transformación de todas las sociedades en sociedades multiculturales (Taylor 1993: 93). El multiculturalismo no se opondría en principio a la política de respeto igualitario. Incluso podría considerársele una continuación de dicha política, en la medida en que incorpora a los derechos civiles y políticos, derechos culturales: "todos deben disfrutar de la suposición que su cultura tradicional tiene un valor" (Taylor 1993: 100). Pero, obviamente, este valor no puede establecerse a través de una norma de derecho positiva. Lo que puede reivindicarse, según Taylor (1993: 102), es una queja frente a los juicios negativos sobre una cultura.

Ahora bien, en la práctica, el jucio afirmativo acerca del valor de una cultura y el juicio que rechaza su desvalorización tienden a confundirse y a hacerse uno. En esto reside uno de los riesgos del multiculturalismo, que obliga en cierta forma a hacer afirmaciones positivas acerca de culturas ajenas, aun cuando éstas no hayan sido realmente estudiadas o sean conocidas.

Esta crítica vale también para muchos intelectuales latinoamericanos defensores del multiculturalismo,

28 Sobre la diferencia entre estas dos concepciones del liberalismo expuestas por Taylor, véase también: Walzer (1993).

29 Al respecto, véase: Gadamer (1960: 372-377). Para éste, "[1]a hermeneútica siempre se propuso como tarea restablecer un acuerdo alterado o inexistente" (1960:362). Por ello, como dice Habermas (1965: 158, 1984: 171; 1968: 241 y 1990: 199), la hermeneútica se orienta por el interés guía de conservación y ampliación de "la intersubjetividad de la comprensión como Bonfil Batalla. Para Bonfil (1989), el reconocimiento de la pluralidad cultural significa el abandono de todo proyecto (unificador y homogenizador) de identidad nacional. La tolerancia y el respeto, aún sin una comprensión mutua, serían la única posibilidad de alcanzar una relación armónica entre los diferentes patrimonios culturales de México. Pero esto excluye otra posibilidad, bien señalada por Taylor (1993: 99), la de la "fusión de horizontes" (Gadamer), o sea, un proceso de comprensión cultural donde la situación hermeneútica u "horizonte" del intérprete logra transformarse y vincularse con la tradición u "horizonte" que se interpreta. ${ }^{29}$ Bonfil (1987 y 1991) agregó, además, otro elemento: la valoración del patrimonio indígena como base de un nuevo México, el "México profundo", con lo que de hecho reestableció una jerarquía entre los diferentes patrimonios culturales y limitó el pluralismo cultural.

El multiculturalismo impone, entonces, de otra manera que la política de respeto igualitario, una homogeneidad frente a todas las culturas. Todas deben ser consideradas en igual valor y derecho, como también sus expresiones. "Si todas las culturas han hecho una aportación valiosa, no puede ser que éstas sean idénticas o que siquiera encarnen el mismo tipo de valor. Esperar esto sería subestimar en gran medida las diferencias" (Taylor 1993: 99).

Esta manera abstracta y homogenizadora de concebir el multiculturalismo puede llegar a convertirse en una norma coercitiva respecto de la expresión y la conducta pública y privada de juicios e ideas en relación con otras culturas, etnias y grupos. Así ocuriiría actualmente en Estados Unidos, según Heller:

"la 'retórica de la raza' ha reemplazado la retórica de la 'cuestión social', lo que significa que también se institucionalizan ciertas reglas de juego definidas para las cuestiones raciales. Estas reglas linguísticas institucionales para cuestiones raciales y de género son obligatorias incluso en el ámbi-

\footnotetext{
orientadora de la acción...del consenso posible de los participantes [Handelnden]"'. Por supuesto, se trata de un proceso de interpretación y diálogo siempre abierto, incompleto, modificable y autocorrectible. A diferencia de Gadamer, nosotros no nos referimos a la interpretación de la propia tradición cultural y su historia, sino que planteamos el problema de la comprensión entre culturas diferentes y contemporáneas
} 
to privado. Ni siquiera en su propia habitación, entre sus amigos, puede uno decir palabras o contar chistes (sobre negros, judios, homosexuales), porque éstos pueden ser malinterpretados. Y quien sea denunciado judicialmente, puede perder fácilmente su trabajo ... Se considera la autorepresentación de un grupo como la única forma legítima de representación de ese mismo grupo. Cualquier representación hecha por otros (por ejemplo, la representación de los negros a través de los blancos, de las mujeres por los hombres, de los homosexuales por los heterosexuales), se considera por definición 'racista' y 'sexista'. La única forma le gítima de vinculación entre las razas (y géneros) es la lucha; la alternativa a ella es el autoaislamiento mutuo y su normalización. Los racistas modernos repiten los viejos argumentos racistas: el otro no puede sentir como yo, tiene otra concepción del conocimiento, ni siquiera puede entender lo que nosotros pensamos, como sufrimos (por su influencia) y así sucesivamente" ${ }^{30}$ (Heller cit. por Beck 1996: 34).

Taylor considera, entonces, necesario encontrar un punto intermedio entre el multiculturalismo entendido bajo la forma de una "exigencia inauténtica y homogenizadora, de reconocimiento de igual valor, por una parte, y el amurallamiento dentro de las normas etnocéntricas, por otra" (Taylor 1993: 106). Sin embargo, esta descripción parece sugerir que nos encontramos ante la alternativa de dos particularismos: el eurocéntrico, que asume el valor de la propia cultura como superior a todas las otras, y las valora según las propias normas, y el multicultural, que considera cada cultura con idéntico valor y las homogeniza a todas. Y encontrar un punto medio entre dos particularismos no soluciona el problema, que queda, a nuestro juicio, mejor planteado como la tensión entre universalismo y particularismo. De esta forma, la cuestión central sería examinar la posibilidad de articulación entre la política de la dignidad igualitaria, que reconoce derechos individuales universales, y la política de la diferencia, que reivindica los derechos colectivos de formas de vida, culturas y etnias particulares. Esto se relaciona con la diferencia entre el libe-

30 Las comillas son nuestras. No hemos tenido acceso a la traducción al inglés de este artículo, donde puede encontrarse la cita de Heller en su idioma original, que nos vimos obligados a retraducir (véase la bibliografía, al final del artículo).

31 Respecto a la interpretación de Habermas, se retoma y desarrolla aquí un análisis anterior (Vergara 2000: 143-149).

32 Walzer (1984: 37 y 40), comete, a nuestro juicio, un error ralismo de la igualdad y el liberalismo de la diferencia. Sólo éste último permitiría reconocer a la vez los derechos individuales universales y los derechos colectivos de grupos étnicos, culturas y religiones.

Sin embargo, esta articulación no es sencilla teórica ni prácticamente. $\mathrm{Al}$ respecto resultan aportadores los planteamientos de Habermas. ${ }^{3 \mid}$ Para Habermas, Taylor plantea equivocadamente la cuestión como una oposición entre dos principios y concepciones del derecho: una, la defendida por liberales como Dworkin y Rawls, que propugna un orden jurídico éticamente neutral, lo que correspondería al concepto de lo justo; y otra, defendida por comunitaristas como Walzer y el mismo Taylor, que consideran válida la promoción de ciertas concepciones de la vida buena, o sea, del principio de 10 bueno (Habermas 1996b: 241-242). Taylor supone que el reconocimiento de derechos individuales choca con, o representa en algún grado un obstáculo para el reconocimiento de derechos culturales. ${ }^{32}$ Habermas (1996b: 243) argumenta, por el contrario, que dicho reconcimiento surge más bien de la "realización consecuente" del reconocimiento a los derechos individuales.

La identidad personal se construye a través de la socialización, está sustentada en vínculos sociales, como el propio Taylor señala en su trabajo. En este sentido, la protección de la integridad individual significa siempre la protección de dichos vínculos. Por ende, el individuo debe seguir siendo el sujeto de derechos, sólo que no debería privársele del acceso a éstos en virtud de sus creencias, cultura o lenguaje. ${ }^{33}$ Si bien es cierto que las identidades individuales están entrelazadas con las identidades colectivas y sólo se pueden estabilizar en una red

similar al de Taylor, al cuestionar la libertad invididual como meta última del proceso de separación institucional al interior de la sociedad, pues la "autonomía institucional" sería la condición de la libertad de los individuos. Si bien el participar o vivir en instituciones autónomas (como las iglesias, las comunidades étnicas, etc.) constituye una condición de la libertad individual, ésta no puede quedar reducida a ella. La libertad sigue siendo un derecho fundamental de cada individuo, lo que incluye su libertad respecto de participar o no en dichas instituciones.

33 Coincidimos totalmente con Michelangelo Bovero cuando afirma: "No creo que exista ninguna tradición aceptable de teoría política que no incorpore en su discurso una teoría del valor de los derechos individuales. En este sentido, cualquiera de nosotros es liberal" (Bovero, 1988: 72-73). 
cultural, "la protección de formas de vida y tradiciones formadoras de identidad debe servir al reconocimiento de sus miembros" (Habermas 1996b: 259).

Habermas propugna una "incorporación sensible a las diferencias", que requiere una separación entre el plano político-jurídico y el ético. Los grupos y subculturas se integran éticamente con su identidad colectiva, mientras la integración política tiene lugar en un plano más abstracto, como integración ciudadana. Pero no se trata de un integración meramente formal, ya que las normas jurídicas tienen un carácter moral; son normas universalistas, como los derechos humanos, distintas a las normas éticas, que sólo tienen validez para los miembros de grupos o subculturas específicas. El derecho sería entonces ética, pero no moralmente neutro. La base de la integración ciudadana es el consenso en torno a procedimientos, pero procedimientos que reflejan los principios universalistas del estado de derecho, integrados a su vez en una cultura política sustentada en el patriotismo de la constitución (Verfassungspatriotismus) (Habermas 262-264). ${ }^{34}$

Desde este punto de vista, no existiría una oposición entre el universalismo de los derechos individuales y el particularismo de las diferencias culturales. Podrían articularse las normas del estado de derecho democrático con el reconocimiento de formas de vidas culturales, religiosas y étnicas.

En este "giro jurídico" de la teoría crítica se desarrollan aspectos que ya se encontraban antes en la obra de Habermas, como la relación entre individualismo y universalismo:

"Individualismo y universalismo son las dos caras de la misma moneda...No se puede tener individualismo sin un universalismo normativo, bajo la con-

34 Taylor (1992: 134) sostiene que el "patriotismo constitucional" fue la base originaria de la unidad nacional tanto en Estados Unidos, país donde surgió, como en Francia, pero que luego hubo un desplazamiento hacia la "etnización del nacionalismo", hacia una idea de unidad "basada en la cultura étnica". En este sentido, la idea de Habermas tendría viabilidad histórica, si bien Taylor advierte, en un tono más crítico. que ninguna forma de unidad política puede ser "definida a priori por el filósofo, como si tuviera que ser teóricamente legítima o admisible, sino que se trata de una unidad que resuite significativa para las mismas personas que componen ese país...No puede tratarse de un principio de unidad definido de una vez y para siempre" (1992: 137). La objeción sería admisible, pero no hace justicia a la idea de Habermas del filósofo o cientista social como un facilitador de procesos de comunicación y entendimiento, no como un demiurgo que puede señalar el modo de vida correcto de una comunidad. dición de no confundir el universalismo normativo con un proceso de normalización, en el sentido de Foucault. No hay que poner la verdad del universalismo moral en el mismo paquete que el imperialismo, pues el imperialismo o el etnocentrismo señalan el rechazo o la incapacidad de tomar un punto de vista moral. Nunca hay un exceso sino una insuficiencia de universalismo" (Habermas, 1988b: 43)

No se trata, como hemos visto, de un universalismo abstracto e indiferente a las diferencias culturales. Si bien las normas jurídicas son universales, no son meramente formales, sino que tienen un contenido moral, que puede entenderse de manera que puedan dar cabida en ellas las éticas propias de grupos y culturas específicas, sin que ello signifique una desintegración social:

"Por supuesto, la coexistencia en igualdad de derechos de diferentes comunidades étnicas, grupos lingǘsticos, confesiones y formas de vida no puede conseguirse al precio de la fragmentación de la sociedad. El doloroso proceso de desacoplamiento no puede desgarrar a la sociedad en una pluralidad de subculturas que se aislen unas de otras. Por un lado, la cultura mayoritaria tiene que desprenderse de su fusión con la cultura política general, compartida en igual grado por todos los ciudadanos. De otro modo, dictaría desde el principio los parámetros de los discursos de autoentendimiento... Por otra parte, las fuerzas vinculantes de la cultura política común que, cuanto más abstracta se haga, tantas más subculturas lleva a un denominador común, tienen que seguir siendo lo suficientemente fuertes como para no permitir que se desmorone la nación de ciudadanos" (Habermas 1996c: 174$175) .^{35}$

35 Este díficil pasaje se encuentra, aunque con varios errores de interpretación e incluso gramaticales, en las páginas 125 y 126 de la traducción española (Habermas 1999: 125-126). Para Habermas, sólo en caso de violaciones flagrantes y sistemáticas de los derechos individuales fundamentales por parte del Estado es justificable la separación de una minoría o grupo étnico de un Estado nacional (Habermas, 1996b: 170-171). Sin duda que en América Latina estas violaciones han sido muy frecuentes, especialmente en el caso centroamericano. Sin embargo, desde nuestro punto de vista, no hay incompatibilidad entre pugnar por la creación de estados de derecho que garanticen efectivamente las garantías individuales y la creación de espacios de autonomía a los grupos étnicos así como de reconocimiento de derechos culturales y colectivos. Con todo, al nivel general que estamos discutiendo no es posible abordar casos particulares y examinar si en algunas de ellos existen razones fundadas para pensar en la separación política como única forma de poner fin a situaciones reiteradas, y muy graves. de violaciones de los derechos básicos de las personas y grupos indígenas. 
La integración nacional debe entenderse entonces en relación con la noción de ciudadanía y la pertenencia a una cultura política universalistas como base del estado de derecho democrático. Se superaría entonces el particularismo de la concepción de la nación-pueblo, como también el universalismo abstracto y limitado de interpretación liberal clásica de las normas individuales. Se plantea una redefinición del concepto de nación de ciudadanos.

La propuesta de Habermas es más desarrollada que la de Taylor respecto a la articulación entre las dos politicas de reconocimiento. Habermas acepta el principio liberal de la separación al diferenciar entre ética y moral; normas jurídicas universales y normas éticas particulares; cultura política común y subculturas (Habermas 1996b: 174-175) ${ }^{36}$. Pero admitir la diferencia no significa perder de vista la unidad. Por ello intenta integrar las dimensiones separadas sin subsumir una a la otra (p. e., reducir la ética a la moral) o excluir una a favor de otra (p. e., los derechos individuales a favor de los derechos colectivos). En este sentido, su planteamiento resulta complejo e integrador. Lo mismo puede decirse respecto de la polémica entre liberales y comunitaristas, que Habermas intenta superar recogiendo aspectos de ambas corrientes e integrándolos en una síntesis nueva.

Indudablemente, el análisis de Habermas no está exento de críticas. Una primera observación ha sido hecha por Kymlica y se refiere a las condiciones culturales que posibilitarían el surgimiento de un "patriotismo constitucional", y que el mismo Habermas reconoce como necesarias:

"Si faltan ciudadanos que posean estas cualidades, las democracias se vuelven difíciles de gobernar e incluso inestables. Como observa Habermas, las 'instituciones de la libertad constitucional no son más valiosas que lo que la ciudadanía haga de ellas"” (Kymlicka 1996: 6).

La cuestión planteada es importante y revela una insuficiencia en el planteamiento de Habermas, que otros críticos también han señalado. Bernstein (1996) sostiene que en Habermas hay una oscilación respecto a este problema. En algunos trabajos da a entender que no es necesario que exista un ethos ciudadano como condición de la estabilidad democrática, bastaría que se cumplieran las condiciones

$36 \mathrm{Al}$ respecto, véase: Walzer (1989). formal-pragmáticas de la comunicación, mientras que en otros sí admite su importancia, como en el texto citado por Kymlicka. Para Bernstein, las referencias de Habermas a las "buenas razones" o "la fuerza del mejor argumento" como fundamentos del debate democrático, son inseparables de un ethos, de una concepción ético-substantiva, pero Habermas tiende a rechazar que su teoría de la democracia y la justicia requiera dicha concepción. ${ }^{37}$

Con todo, la crítica de Kymlicka no considera que, para Habermas, la creación de una cultura política democrática es un proceso ligado a la transformación o reforma de las instituciones políticas. Por tanto, no se puede considerar que una u otra deban ser satisfechas de manera exhaustiva previamente al cumplimiento de la otra.

En este sentido, la cita de Raz hecha por Habermas parece sustentar el comentario de Kymlicka:

"El multiculturalismo, aunque apoya la perpetuación de muchos grupos culturales en una misma sociedad política, también requiere la existencia de una cultura común" 38

Podría argumentarse plausiblemente que en nuestro país falta dicha cultura común. No obstante, la cita se presta a confusión. Si existiera una cultura compartida por todos, dejaría de existir el problema del respeto de las diferencias culturales, del multiculturalismo. Por el contrario, éste se plantea precisamente en la medida que se reconoce que existen tales diferencias. Esta cita viene, de hecho, justo después del texto de Habermas citado más atrás, donde éste habla de una "cultura política común", lo que se refiere a un aspecto parcial de una totalidad que es siempre más compleja. Así y todo, en casos como el nuestro, parece también díficil pensar que pudiera crearse al corto o mediano plazo un consenso compartido respecto a cuestiones como la ciudadanía cultural. En este sentido, los planteamientos de Habermas tienen un valor más propositivo que descriptivo, a diferencia de lo que

37 En un plano más general, Bernstein (1996) cuestiona incluso la distinción entre ética y moral propuesta por Habermas. cuestión que aquí no puede tratarse. Sin embargo, resulta importante al menos mencionarla, dadas las consecuencias que el propio Habermas extrae de esta diferencia.

38 Joseph Raz, "Multiculturalism: A Liberal Perspective", en: Dissent, Winter 1994, pág. 77, cit. por Habermas (1996b: 175). La cita ha sido traducida del inglés por nosotros. Puede consultarse la traducción hecha para la edición española del libro de Habermas (1999: 126), a nuestro juicio poco satisfactoria. 
ocurriría en países con mayor tradición cívica. $\mathrm{Na}-$ turalmente, que un esfuerzo en este sentido sólo puede concebirse como una conjunción de fuerzas tanto del Estado como de la sociedad. Por ende, no puede ser impuesta por el primero.

En la mentada "inclusión sensible a las diferencias", Habermas es claro en precisar que el tema es distinto si nos enfrentamos: (a) al feminismo; (b) a las minorías étnicas y culturas oprimidas, $o$ (c) al:

"nacionalismo de poblaciones que se comprenden como grupos étnica y lingüisticamente homógeneos desde el transfondo de un destino histórico común y que quieren asegurar su identidad no sólo como comunidad de origen, sino en la forma de un pueblo-Estado (Staatsvolk) capaz de actuar políticamente" (Habermas 1996b: 248 Habermas 1999: 199).

Este punto no deja de ser relevante, porque es posible que la tensión en el movimiento mapuche se de en la forma de cómo autocomprenderse, entre (b) y (c). Si esto es así el tema relativo al "patriotismo constitucional" debería precisarse más. El concepto parece demasiado amplio como para incluir de manera diferenciada los distintos casos, sobre todo el tercero. Kymlicka argumenta, siguiendo a Taylor, A. Smith y Lenoble, que "los valores compartidos no son una base suficiente para la unidad, y que también se debe prestar atención a las cuestiones de identidad" (Kymlicka 1996: 259, nota 15). Sin embargo, ha omitido aquí la distinción entre normas éticas y morales que, como hemos visto, da al planteamiento de Habermas una mayor complejidad. La existencia de distintas concepciones éticas, arraigadas en distintos grupos, no necesariamente niega la posibilidad que haya valores morales (universalistas). Por esto, la propuesta de Habermas es más "realista" que la de muchos de sus críticos, que excluyen ex profeso las cuestiones normativas y sustentan una visión de la política como una lucha fáctica, de manera similar a Weber, Bobbio, Foucault o Carl Schmitt. No obstante ello, la distinción entre diferencias de género, minorías étnicas y culturales y minorías nacionales exigiría un tramamiento más desarrollado en relación con el problema de su integración ciudadana.

La importancia de esta propuesta en el marco latinoamericano díficilmente puede ser exagerada. El debate sobre cuestiones étnicas en la región ha os- cilado en gran medida entre una defensa de los principios de igualdad jurídica, unidos estrechamente a la concepción de una identidad nacional hómogenea, y una defensa anti-liberal de los derechos étnicos y colectivos. ${ }^{39}$ Para citar un texto paradigmático, un editorial de la revista América Indígena, órgano de difusión del Instituto Indigenista Interamericano, en 1979:

"En los modelos de Estado nacional que heredamos de Europa, subyacen ciertas premisas que se contradicen por la presencia y vehemencia de estos movimientos..$^{40}$ En su búsqueda de mayor autonomia regional éstos socavan las tendencias centralistas de los gobiernos nacionales. Su argumento filosófico sobre lo que ellos definen como igualdad no concuerda con lo que los Estados propugnan. Para éstos la igualdad es igualdad individual ante la ley, mientras que para los grupos étnicos igualdad es reconocer el derecho a ser diferentes y frecuentemente presionan para que estas diferencias sean reconocidas" (América Indígena 1979: 433).

Como puede verse en el texto recién citado, aquí se están oponiendo dos conceptos de igualdad: el de la igualdad jurídica individual, y el de la igualdad cultural y colectiva. Los argumentos que hemos presentado aquí sustentan una posibilidad hasta ahora poco considerada o insuficientemente desarrollada, la de una articulación entre ambas formas de igualdad y su correspondencia en el plano jurídico-político, sin derivarse de ello una noción de autonomía fuerte, en el sentido de separación de los grupos étnicos de los estados nacionales.

Indiscutiblemente que la existencia de argumentos contrarios a la idea liberal-universalista de derechos individuales es históricamente comprensible. Aún

$39 \mathrm{Al}$ hacer este contraste no pretendemos, en modo alguno, afirmar que el debate europeo sea superior en algún sentido a la discusión latinoamericana, donde se encuentran también autores cercanos a la posición que estamos defendiendo de vinculación entre universalismo igualitario y diferencias culturales. Nos referirmos sólo a las tendencias generales. Por otro lado, la posición de Habermas respecto de las corrientes dominantes en el Primer Mundo, donde predominan visiones escépticas y antiracionalistas, es minoritaria y excepcional (Bovero 1988: 76-77, Vergara 1990: 269-270). Lo mismo vale para Taylor.

40 Se refiere a los nuevos movimientos indígenas surgidos en la década de 1970 . 
con mayor fuerza que en Europa o Estados Unidos, existen en América Latina desigualdades fácticas que contradicen abiertamente dicho principio. El caso de los pueblos indígenas de la región es muy claro al respecto y no requiere mayores comentarios. Adicionalmente, cuando los Estados han enfrentado dichas desigualdades, como en el caso de México, lo han hecho con una concepción integracionista radical, que pretende fundar la integración nacional en una única identidad cultural. ${ }^{41}$

Junto con ello, en nuestros países, el liberalismo, sobre todo el liberal-positivismo del siglo XIX, se ha amalgamado a menudo con concepciones evolucionistas, racistas y discriminatorias. Todo ello hace entendible el rechazo de los principios liberales por muchas organizaciones étnicas, así como por intelectuales indígenas y no-indígenas simpatizantes de sus causas. No obstante, como se desprende de la discusión anterior, la noción de derechos individuales y el mismo liberalismo no pueden ser reducidos a una ideología de poder. Dichos derechos constituyen principios universalizables cuya validez puede ser separada de la interpretación y aplicación estrechas que se les ha dado históricamente por las élites y oligarquías dominantes latinoamericanas. Asimismo, el liberalismo no es una corriente homógenea. Existen al menos dos grandes interpretaciones antagónicas que derivan ambas del liberalismo clásico de los siglos XVII y XVIII (Hobbes, Locke, Smith), el "liberalismo posesivo" "2: el liberalismo democrático (Mill, Dewey, Laski) y el neoliberalismo (Hayek, Popper, Friedman). ${ }^{43}$ Esta última corriente rechaza la idea de igualdad natural de los hombres, formulada por el liberalismo clásico; mientras el liberalismo democrático la desarrolla más allá de la igualdad política y jurídica, incluyendo la igualdad económica y social (Vergara 1997). Otro tanto ocurre con la idea de justicia (Vergara 1995). Indiscutiblemente, esta última corriente es la que está más cerca de una concepción democrática participativa, donde pueda darse cabida a los derechos colectivos y culturales de grupos étnicos, sin dejar de lado los derechos individuales.

Interpretar los principios de igualdad jurídica indi-

41 Nos referimos, obviamente, al indigenismo. Para una caracterización crítica, véase, entre otros: Bonfil Batalla (1985), Bengoa (1995 y 2000, cap. 2: 50-85) y Del Val (1993).

42 Remitimos al estudio clásico de MacPherson (1962).

43 Sobre la diferencia entre estas dos corrientes, véase: Bachrach (1967), Mac Pherson (1976) y Vergara (1989). vidual como mera expresión de una cultura dominante significa, además, reducirlos a pura facticidad. sustrayendo del análisis los aspectos normativos. Así se muestra en un trabajo reciente de un destacado colega antropólogo, J. C. Skewes (1999). Basándose en el caso de una mujer mapuche que en 1953 dio muerte a su abuela acusándola de haberla embrujado y fue absuelta por el Juzgado de Letras de Valdivia ${ }^{44}$, Skewes define la coexistencia de normas jurídicas occidentales y mapuches como una oposición entre "principios morales", que "díficilmente pueden reconciliarse bajo el imperio de un predicamento universal". Evidentemente, aquí no aparece la distinción entre ética y moral que encontramos en Habermas. Todo sistema jurídico es expresión de una cultura particular, y esto incluiría al sistema occidental y sus normas aparentemente universalistas.

Skewes plantea, sin embargo, la posibilidad de diálogos interculturales que "pueden ser conducentes a la legitimidad de cualquier cuerpo legal que aspire a una cierta universalidad". El fallo del juez exculpando a la mujer mapuche sería expresión de esto. Sin embargo, su interpretación acerca del derecho circunscribe esta posibilidad a la mutua tolerancia. Si cada sistema jurídico representa un dominio moral propio, entonces no es posible encontrar un principio moral universal, o éste, de haberlo, sólo podría ser un principio formal, como el respeto a cada sistema jurídico y sus normas morales específicas. En este caso, subsistiría la dificultad de qué hacer frente a una divergencia en torno a una situación específica, como la producida aquí.

Siguiendo las declaraciones de la acusada y de otros mapuches que prestaron testimonio en el juicio, Skewes considera que el acto de violencia cometido por la mujer fue "un medio de defensa de su propia persona y de la comunidad a la que pertenece" (1999: 92). Más aún, Skewes aboga por un efectivo reconocimiento de esta capacidad colectiva de defensa, ya que:

"Lo que la muerte de la bruja pone de relieve es la existencia de dominios legales contradictorios, el

44 Se trata de Juana Catrilaf, residente en la zona de Panguipulli. en la provincia de Valdivia. El fallo se apoyó en un informe antropológico en el que participaron varios destacados especialistas de la época, entre ellos, Alejandro Lipschutz (Jurisprudencia 1956 y Boletín, 1956). 
uno que se impone con el peso del estado, de la ley $y$ de la institucionalidad jurídica, y el otro que prevalece en el margen" (1999: 92)

La existencia de un sistema jurídico impuesto a los mapuches por sobre el propio es en sí misma una amenaza para esta comunidad:

\section{"El juicio fácil, fundado en la pura presunción de la primacía de un sistema sobre otro, amenaza con convertirse en la bruja del presente, aquella que 'acecha en la noche oscura', amenazando al pue- blo mapuche con su extinción" (1999: 92).}

Siendo así, uno podría suponer que toda forma de resistencia a dicha amenaza es válida, como válido habría sido el dar muerte a la mujer acusada de brujería. Su condición de dominados, que obviamente no negamos, significaría que los mapuches podrían utilizar la violencia en defensa de su cultura que peligra extinguirse. Aún con consecuencias de muerte. De otro modo, habría que aceptar que ciertos principios, como el derecho a la vida, son universales y deben ser respetados por cualquier cultura, independientemente de quién establezca esto como norma jurídica. ${ }^{45}$

La analogía entre la "bruja" asesinada y el sistema legal chileno es lamentable, pues entonces este último no es más que una agresión, es expresión de pura dominación. En cambio, el sistema legal mapuche representa un mecanismo de defensa de la comunidad. En un lado, hay poder puro; en el otro,

45 Es justamente esta ausencia la que hace cuestionable la argumentación de Aravena y Hervé, en su informe pericial al Juez del Décimo Octavo Juzgado del Crimen de Santiago, de agosto de 1994, el que se refiere al caso de un joven mapuche acusado de homicidio. Aravena y Hervé argumentan, en forma similar a Skewes, que el acusado actuó en defensa de su pueblo y familia mapuches. En efecto, "La sociedad mapuche es una sociedad altamente coercitiva, en cuyo seno la sanción social y comunitaria opera a modo de justicia y sin embargo, personalidades pertenecientes a su propio pueblo destacan la dignidad de la conducta asumida por Antipan frente a su familia y a su pueblo" (Aravena 2000: 150). Esto debe entenderse a su vez en el contexto de la cultura mapuche, donde el rol de cabeza de familia ejercido por el varón contiene obligaciones de proteger a todos sus miembros: "el haber asumido otra conducta no sólo hubiera puesto en peligro su propia vida ante la amenaza constituida por la provocación y la actitud de su oponente, de acuerdo a sus propios dichos, sino que habría puesto en peligro la seguridad de su familia, sufriendo el desprecio o menoscabo de su dignidad frente a su grupo familiar, del que es jefe y pater familia, la comunidad indígena a la que pertenece" (Aravena 2000: 150). Si esto es así, justicia pura. No sólo se ignora aquí la dimensión de poder que puede existir en la cultura mapuche, en la que el tema del sacrificio no ha estado ausente, como no lo ha estado en la cultura occidental ${ }^{46}$, sino que se descarta por principio toda validez del sistema legal nacional para la cultura mapuche en cuanto es parte de la dominación que ejerce la sociedad chilena sobre ella.

Díficilmente puede ser esta la base para una discusión sobre multiculturalismo y pluralismo legal. Sólo sobre un reconocimiento mutuo y no la mutua negación de cada cultura podría surgir el diálogo al que Skewes y nosotros mismos aspiramos. Además, hay una evidente contradicción, porque aunque el fallo de la Corte fuera expresión de un diálogo a favor del pluralismo legal, como sostiene Skewes, no deja de ser una decisión tomada desde el sistema legal impuesto. Y por tanto lo que cabría no es reivindicar la apertura de dicho sistema al sistema mapuche, sino declarar la absoluta ilegimitidad del primero para juzgar al segundo $y$, consecuentemente, plantear la necesidad de un reconocimiento in totu de los mapuches a darse sus propios principios de justicia. Se trata de la única posibilidad de convivencia entre dos particularismos normativos sostenidos por cada comunidad respectiva. Si lo universal no es posible sólo queda la tolerancía completa, o, en otro caso, el enfrentamiento por cualquier medio. La lucha política y discursiva por el reconocimiento pierde su carácter moral, de búsqueda de un aprendizaje mutuo. Se reduce a un conflicto de fuerzas. La política de la dignidad igualitaria

cualquier crimen cometido por un mapuche podría tener como atenuante justificaciones de este tipo, la defensa de la dignidad como pueblo. El derecho a la vida quedaría suspendido o reducido en su vigencia cuando se arguyeran razones de defensa étnica, incluso si, como en este caso, parecen haber pocas pruebas que la agresión de que fue objeto el joven mapuche tuviera algún móvil discriminatorio o racista. La presentación del abogado defensor, basada en el informe pericial, incluso da la pertenencia étnica del acusado como atenuante en sí misma, ya que "factores étnicos le privaron de la inteligencia y libertad suficientes como para que hubiera podido asumir otra actitud distinta"; su forma de reaccionar como mapuche es "totalmente diferente a la de cualquier otro nacional" y difiere "notablemente de nuestro comportamiento normal frente a una situación de peligro personal o familiar, especialmente por un diferente concepto de honor y valor" (Aravena 2000: 151). Esto es tanto como decir: por ser indígena, no disponía de la capacidad de encontrar otra forma de hacer frente a una reacción diferente.

46 En la obra más reciente de Hinkelammert y de Girard; y, en nuestro medio, de Pedro Morandé, se ha abordado exhaustivamente este tema. 
no podría articularse con una política de la diferencia cultural.

De una manera más radical aún que en el caso del principio de igualdad y los movimientos étnicos según el Instituto Indigenista Interamericano, los planteamientos de Skewes respecto a la justicia muestran la tendencia de muchos autores latinoamericanos a oponer radicalmente los principios universalistas liberales con las normas propias de cada grupo étnico. El énfasis que, en temáticas como la indígena, se suele conceder a lo "particular, cambiable y contingente", dice MacCarthy "es una reacción comprensible frente a la preocupación tradicional con lo universal, lo atemporal y lo necesario", pero no deja por ello de ser "menos unilateral ni menos cuestionable en sus consecuencias prácticas. Prescindir de lo ideal en nombre de lo real es tirar el bebé con la bañera" (MacCarthy 1989: 208).

Las nociones de libertad, justicia e igualdad y las normas jurídicas a través de las cuales se expresan son formas en las que las sociedades modernas se determinan a sí mismas el sentido de su convivencia, y no mera expresión de relaciones de poder fáctico. Habermas ha desarrollado esto en relación con la teoría crítica. Dicha teoría intenta "la reconstrucción de una autocomprensión normativa de los órdenes políticos modernos" que "no es 'empírica' en el sentido de las ciencias exactas"; se entiende "como algo que esbozamos en las presuposiciones de nuestras prácticas y no sólo como una autocomprensión normativamente esbozada" (Habermas 1996c: 168). En una veta similar, Taylor ha hablado de "normas constitutivas" de las prácticas, o sea, aquellas normas que le dan sentido a una cierta práctica social y son, por tanto, inseparables de ella, como por ejemplo, la "práctica de la decisión mayoritaria" dentro de una democracia (Taylor 1985). Este es el caso de las nociones que hemos señalado.

Lo que las ciencias sociales pueden hacer es contribuir a incentivar y aclarar los procesos sociales de autoaprendizaje y fortalecimientio democrático. La idea hegeliana de lucha por el reconocimiento comprende precisamente esta dimensión normativa. Se trata de entender el conflicto en torno a la definición de estos principios constitutivos como parte de un posible acuerdo y consenso fundado en la igualdad de los actores.

En su aspecto empírico, que es el que desarrollare- mos a continuación, este enfoque requiere reconstruir las concepciones subyacentes y el conflicto por el sentido y amplitud del reconocimiento, considerando entonces los aspectos normativos, junto a los elementos de poder que están presentes en dicho conflicto.

\section{La lucha por el reconocimiento en el caso mapuche $^{47}$}

Intentaremos ahora mostrar los modos cómo se articulan y oponen las exigencias de reconocimiento de los mapuches con las políticas de reconocimiento de parte del Estado chileno y la forma cómo unas y otras son conformadas por parte de El Mercurio, verdadero "intelectual orgánico" de la élite dominante chilena. Para el decano de la prensa chilena, la política de reconocimiento étnico de los gobiernos de la concertación representa un error fundamental de visión y estrategia. Crea las posibilidades de desarrollo de un movimiento indigenista radicalizado, violento y sececionista. Por ende, se ven amenazados el estado de derecho, el orden público, el crecimiento económico y, lo que es más importante, la unidad de la nación.

El otro extremo lo encontramos en el discurso etnonacionalista mapuche, un discurso que potencialmente supone una separación drástica y definitiva, simétrica con la de El Mercurio, entre lo mapuche y lo chileno, sin que sea posible entonces vislumbrar un horizonte común que permita el entendimiento de ambos ni haga posible comprender las relaciones actuales más que a modo de negación, autonegación y opresión de la cultura mapuche. Esta visión tiene antecedentes en la intelectualidad mapuche desde los años 70 's, ${ }^{48}$ pero ha adquirido una nueva dimensión con la presencia de un discurso que llama a poner en práctica la separación efectiva del mundo mapuche vía la (re)creación de la nación mapuche.

La postura mapuche.

Es posible distinguir tres tendencias o formas de búsqueda de reconocimiento en el seno del pueblo

47 Esta sección del artículo reproduce en parte un trabajo anterior de uno de los autores (Foerster y Lavanchy 1999: 65-102).

$48 \mathrm{Al}$ respecto, véase: Kotov y Vergara (1997). Este tema ha sido abordado extensamente por Sara MacFall en su tesis doctoral (MacFall, 1998). 
mapuche. Una es la campesina, muy fácil de detectar en el universo de las demandas como también en las movilizaciones..$^{49}$ La literatura autobiográfica también nos muestra como numerosos mapuches se autocomprenden como pequeños campesinos (en la mayoría de los casos empobrecidos).

Una segunda tendencia es la étnica, se trata de una demanda de reconocimiento muy generalizada y que se ha expresado en múltiples formas a lo largo de todo el siglo XX en torno a la lengua, la memoria y las creencias religiosas mapuches. Su manifestación política ha estado asociada a organizaciones como la Federación Araucana y la Corporación Araucana en el pasado; en el presente a ADMPU, Junta de Caciques del Butahuillimapu, etc.

Una tercera tendencia es la "etnonacional", más reciente y que merece que le demos un mayor espacio por tratarse además del discurso que domina hoy en las organizaciones más activas en los conflictos con empresas privadas, propietarios de tierras y el Estado.

"Nos encontramos --dice Víctor Naguil-- no sólo ante un conflicto por tierra o territorio, sino ante un conflicto étnico-nacional --por lo tanto integral-- que enfrenta a la nación mapuche con el Estado chileno" (Naguil 1999: 39). En esta escueta pero enfática afirmación se sintetiza la forma como este importante segmento de la dirigencia y la intelectualidad mapuche define el carácter de sus reivindicaciones.

La política gubernamental de reconocimiento étnico es cuestionada severamente por esta corriente. Para el Consejo de Todas las Tierras, la ley indígena ni siquiera merece llamarse tal: es una ley hecha

49 A modo de ejemplo, véase la declaración de Sergio Bustamante Chacón, delegado de la comunidad mapuche Mauricio Hueitra, de agosto de 1972: "Somos muy modestos. Somos campesinos. Somos indígenas" (El Correo de Valdivia, 26 de agosto de 1972, págs. 1 y 6, Valdivia). Un análisis detallado de las demandas mapuches, sobre todo durante las décadas de 1960 y 1970. conobora la importancia del tema campesino en ellas (Foerster y Montecino 1988). Por cierto, en este período aparecen también demandas étnicas, e inclusive el rechazo a la campesinización. De acuerdo a una crónica periodístíca de Eusebio Painemal, en enero de 1961, las comunidades de Cautín se movilizaron contra la ley indígena y la subdivisión de las comunidades pues, de otro modo, "A corto plazo serán campesinos como todos los que no tienen tierras y que van de hecho a terminarse y a extinguirse como raza" (cit. por Foerster y Montecino 1988: 302). por y para el Estado. ${ }^{50}$ Aunque en otras cuestiones discrepe con el Consejo, el asesor de la Meli Wixan Mapu y vocero de la Coordinadora de Comunidades en Conflicto en Santiago, Alihuen Antileo, coincide en este punto. La ley es ajena al pueblo mapuche, porque no reconoce la nación mapuche. Hablar de "minoría étnica" o de "pueblos originarios" es imponerles una definición desde fuera y con el fin de mantenerlos oprimidos. Sólo la definición de nación es propia y es en base a ella que el Estado y la sociedad chilena deben tratarlos. ${ }^{51}$ Así,

"cuando nosotros decimos que somos una nación, corresponde a nuestra definición y por lo tanto cuando nos definimos con ciertas características determinadas, queremos que se nos trate y se nos defina de acuerdo a una nación" (Antileo 1999: 5).

En consecuencia, la relación con el Estado chileno se entiende como un conflicto abierto, permanente y global. Para Antileo, de no producirse un cambio fundamental de parte del Estado chileno, las movilizaciones y acciones de los mapuches se transformarán en una lucha por la "liberación nacional". 52 En dos documentos sucesivos, dados a la luz en marzo y junio de 1999, la Coordinadora estableció como objetivo "la lucha por reconstruir nuestra Nación y nuestra historia" y situó la ocupación đe predios en disputa con empresas forestales "bajo un proyecto rearticulador de comunidades que vaya perfilando la idea de la reconstrucción de la Nación Mapuche, con un pensamiento y distintas formas de organziación para un destino propio". El Enlace Mapuche Internacional/Mapuche International Link habló en mayo del mismo año, en términos similares, de "la reconstitución del Meli-Butalmapu y la

50 "La ley propagandizada como ley indígena no es tal, no sólo por haber sido elaborada por funcionarios estatales, sino también porque no responde a las verdaderas necesidades y reclamos de justicia del pueblo mapuche, ni de los demás pueblos originarios del país" dice un libro publicado por el Consejo de Tierras en 1997 (Aukiñ Wallmapu Ngulam, 1997: 71).

51 Este es justamente el problema sobre el que llama la atención Heller, en el texto citado en el apartado anterior, la exigencia de autorepresentación y el cuestionamiento de toda representación externa.

52 "Llevamos 500 años de resistencia, pero en esta nueva etapa decimos que toda expresión cultural, de rescate de nuestras tradiciones es válida, lo que llevará en algún momento a la etapa que nosotros llamamos de rebelión, una vez que tengamos masificado el concepto, y si no se producen los cambios necesarios respecto de un estado que nosotros denominamos opresor, no de integración, tendrá que llegar necesariamente una etapa de Liberación Nacional, y esto es en el plano político, cultural y en el plano militar" (Antileo 1999: 6). 
creación de un gobierno provisional" y de "transformar el territorio ancestral mapuche, en una zona desmilitarizada, bajo el protectorado y control de las Naciones Unidas, con el objeto de prevenir el desarrollo de un conflicto con consecuencias imprevisibles".

Por cierto, entre los intelectuales y dirigentes etnonacionalistas mapuches existen diferencias de pensamiento y estilo de acción. La Coordinadora refleja, probablemente, la visión del sector más radical dentro del movimiento. Otros no hacen una distinción tan tajante entre el Estado chileno y la "nacionalidad" mapuche. Apelan a la sociedad chilena a reformular del concepto unitario del Estadonación chileno y su reemplazo por uno de tipo multinacional. El poeta e intelectual Elicura Chihuailaf afirma, en su obra más reciente, que la lucha de los mapuches, en tanto pueblo o "Pueblo Nación", "tiene que ver con los derechos individuales" pero no se agota allí: "Lo que deseamos como Pueblo, es el reconocimiento de los derechos colectivos como pueblo distinto. Es decir: somos un Pueblo distinto con derechos inherentes". Y añade: "la redefinición de este país tendrá que incluir, en nuestra perspectiva, el reconocimiento de nuestros derechos colectivos como un Pueblo Nación distinto" (Chihuailaf 1999: 203-206). El mismo Consejo de Todas las Tierras adopta una posición similar en un importante documento de 1997 :

"La Nación mapuche exhorta al pueblo chileno a producir una nueva relación, considerando el estado de negación en que se nos mantiene a ambos y la privación del ejercicio de nuestros derechos" (Aukin Wallmapu Ngulam, 1997: 111).

Con uno u otro matiz, es indiscutible que esta perspectiva ha ido ganando fuerza en los últimos años, y especialmente en el año anterior. Aunque tímidamente, algunos analistas del movimiento indígena reconocen este fenómeno. Dos obras destacan en este punto, la de Bengoa (1999a) y la de Barrera (1999). Veamos algunas citas:

“...estos jóvenes ilustrados comienzan a retomar ideas también antiguas pero de manera diferente.

$53 \mathrm{Al}$ respecto, véase: Foerster y Lavanchy (1999: 76-80).

$54 \mathrm{Vida/muerte,} \mathrm{según} \mathrm{Anderson} \mathrm{(1993:} \mathrm{25):} \mathrm{“} \mathrm{(La} \mathrm{Nación)} \mathrm{es}$ esta fraternidad...que ha permitido, durante los últimos dos siglos, que tantos millones de personas maten y, sobre todo, estén dispuestas a morir por imaginaciones tan limitadas".
Hablan de autogobierno, de autonomía, de autodeterminación de los Pueblos Indígenas" (Bengoa 1999a: 230).

Para Bengoa, que conoce muy de cerca la dirigencia mapuche, esta idea de autogobierno y de autodeterminación se refiere a un "derecho sustantivo". De allí que "tarde o temprano los autodesignados pueblos llegan a plantear el tema de la autonomía" (1999a: 233). No obstante, en términos generales, Bengoa (1997) considera que lo étnico y lo nacional no deben ser confundidos. Su propio planteamiento se basa más bien un cuestionamiento de la idea de "la unidad entre pueblo, nación y Estado" y reconocer, como lo haría hoy la visión "moderna" de la democracia, que

"la valorización de la diversidad del pueblo y esa diversidad forma[n] una nación más rica... No se debilita la identidad del Estado ni la nación si se reconocen en el interior del pueblo chileno numerosas diversidades" (Bengoa 1999b: E/7).

Si se revisan las actuales propuestas de las organizaciones mapuches encontraremos numerosos elementos que permiten señalar que está en gestación dicho horizonte. ${ }^{53}$ El mismo temor de El Mercurio contribuye a esa gestación (a la manera de una profecía autocumplida), igualmente las políticas del gobierno (aunque como efecto no esperado).

La pregunta que surge es qué grado de divulgación y sobre todo qué fuerza emotiva tiene este "etnonacionalismo" mapuche ${ }^{54}$ Sobre este punto no hay antecedentes claros, pero permítasenos reproducir un comunicado público de una de las tomas del mes de noviembre de 1999 , en la cercana ciudad de Temuco:

"A nuestros hermanos en el mundo desde nuestro mundo mapuche. Siendo las 6:30 de la mañana de hoy lunes 29 de noviembre, hemos iniciado el proceso de recuperación territorial Wenteche. El territorio de Xuf Xufy sus Ayjarewe. A pesar de la dura respuesta armada que se nos dio en el fundo, prevaleció nuestro espiritu combativo y por siempre libertario mapuche. Tres heridos de mediana gravedad, de los oponentes, fue el resultado de la refriega. Doce lof mapu organizados, que significan, Pu papay, pu lamgen. pu peñi, pu logko, pu koha, hemos dicho, presente, aun estamos vivos. A pesar de la marginación y la pobreza en que nos encon- 
tramos, no hemos perdido nuestra dignidad. Hemos sacrificado a muchas generaciones de los nuestros, forzandolo a emigrar de su territorio ancestral, condenarlo a vivir muchas veces en la marginalidad de los grandes centros urbanos. Pero todo tiene un limite, señores autoridades de este reciente pais, denominado CHILE.

"Basta de pobreza, marginación, discriminación y despojo territorial, cultural, religioso, político, social y económico. Por nuestros derechos, por nuestro pueblo, por nuestros hijos y su dignidad a vivir en un territorio digno. iTus hijos estamos aún vivos y dignos! 'Rumel newentuleayiñ! ¡Por siempre haremos fuerza! ¡Rumel Wewküleayiñ! ¡Por siempre triunfaremos! Desde el territorio de Xuf Xuf.

"José Quidel Comunicación Exterior.

"Organización Wenteche Ayjarewegetuayiñ"

El tono de esta declaración no existía hace veinte años atrás, tampoco sus términos ("nuestros derechos, nuestro pueblo"). Aquí se habla de "territorios" recuperados al Estado chileno, que responde con la fuerza. También se apela a la dignidad, pero no individual sino colectiva, como pueblo. Se mencionan la pobreza, la discriminación, la marginación y el "despojo terrritorial, cultural, religioso, político, social y económico", cuestiones que no son nuevas dentro del discurso mapuche, pero que ahora aparecen claramente vinculadas a un gran tema, el del territorio mapuche. Si bien no se habla de "nación mapuche", está supuesto que la recuperación de dicho territorio habría de significar también la autonomía dentro de él.

Queremos insistir que la actual problemática del reconocimiento vía la "nación mapuche" y como expresión de un proyecto liberador ${ }^{55}$, está abierta en el seno de la sociedad mapuche y que su camino no será fácil. Como hemos señalado, este tipo de reconocimiento se cultiva hasta ahora en la élite del movimiento mapuche, y está en tensión con otras demandas de reconocimiento (campesina y étnica).

Asimismo, la existencia de un discurso etnonacional compartido por intelectuales y dirigentes políticos no significa necesariamente que exista un movimiento nacionalista mapuche propiamente tal. El nacionalismo o etnonacionalismo, siguiendo los términos de Connor, son fenómenos de masas. Por ende, el rol de las élites intelectuales y políticas no debe ser exagerado (Connor 1994: 85). Si bien en las pri- meras fases de formación del movimiento dichas élites juegan un papel considerable, éste requiere del apoyo de la mayoría de la población del grupo étnico para aspirar a tener éxito, debe convertirse en un fenómeno de masas. De acuerdo a Hroch (1993: 81) existirían tres fases de formación de un movimiento etnonacional. En la primera fase a

"las energías de los activistas están dedicadas dedicadas sobre todo a la indagación documentallacadémica (scholarly inquire) y a la diseminación de una conciencia de los atributos linguísticos, culturales, sociales y, algunas veces, históricos del grupo no-dominante".

Esto supone, obviamente, una presencia importante de los intelectuales. En una segunda fase (fase b), en cambio, se acentúa el papel de los líderes políticos que buscan "despertar" la conciencia nacional de su grupo étnico y ganarlo para sus proyectos, "encontrando una audiencia crecientemente receptiva". Finalmente, en la tercera fase (o fase c), se habría formado un movimiento de masas apoyado por la mayoría de la población. Aquí el rol de las élites sería secundario respecto de dicho apoyo masivo.

Por otro lado, y como hemos dicho, esta tendencia convive con otras dentro del movimiento indígena y la sociedad mapuche. Su éxito dependerá, en gran medida, de incorporar las demandas campesinas y étnicas, dándoles un nuevo sentido, en forma similar a cómo la tendencia étnica había integrado la demanda campesina, subordinándola dentro de un esquema diferente. La misma diferenciación interna del movimiento mapuche representa un obstáculo para llevar a cabo esto con éxito. Implícitamente, los líderes etnonacionalistas reconocen el proble-

55 Touraine (1997: 206) ha destacado recientemente la dimensión liberadora del nacionalismo: "La nación es la figura política del Sujeto porque, como toda figura de éste, asocia una actividad instrumental a una identidad cultural al constituirse en espacio de libertad". Pero este reconocimiento nacionalista tiene sus límites: "El nacionalismo es un fenómeno específicamente modemo, porque sustituye la relación de señorío y servidumbre por un reconocimiento mutuo o igual. Pero no es plenamente racional, porque ofrece el reconocimiento sólo a los miembros de un grupo étnico o nacional dado" (Fukuyama 1992: 362). Esto último es válido siempre que se trate de una concepción de nación-pueblo, Volksnation. Distinto es el caso de la concepción republicana de la nación de ciudadanos, Staatsnation. Véase, al respecto el apartado anterior, y sobre todo los trabajos de Habermas citados en la nota 12 . 
ma, al plantear la necesidad de unir al movimiento y dar cabida a las demandas más inmediatas y acuciantes de las comunidades, por ejemplo, la recuperación de tierras. Pero aquello que es una construcción de hegemonía es visto, sin embargo, como una reconstrucción de una unidad Cuasi natural, la unidad nacional mapuche.

Por ende, retomando la distinciones de Habermas, podría decirse que la concepción de nación dominante en las élites etnonacionales mapuches corresponde mutatis mutandis a lo que Habermas denomina una nación-pueblo. En efecto, se subrayan los lazos de descendencia de un ancestro común, la lengua y la cultura mapuche en general, como elementos propios y distintos de los de la sociedad chilena. Asimismo, se enfatiza lo territorial, la recuperación del territorio ancestral. La legitimidad de las ocupaciones de tierras radicaría aquí, aún cuando no haya un título de propiedad otorgado por el Estado, como se muestra en las reivindicaciones de "tierras antiguas", las jurisdicciones de lonkos anteriores a los títulos de merced. ${ }^{56}$ Aquí se hace patente la diferencia con las ocupaciones de los años sesenta y setenta, que se orientaban hacia la recuperación de terrenos con títulos de merced.

La nación no se entiende como una pertenencia a un espacio político compartido o por construir. Tampoco como una forma de ciudadanía ampliada dentro del estado-nación chileno, como una ciudadanía cultural. ${ }^{57}$ Por ende, los presupuestos que dan sentido a un estado de derecho democrático, como los derechos individuales, si bien no son explíticamente rechazados, tienden a ser interpretados como la manifestación de una concepción de sociedad y de organización distinta a la mapuche y, por tanto, extraña a ella. La política liberal de reconocimiento

\footnotetext{
56 Al respecto, veáse: Vergara et al (1999: 119-122).

57 Sobre la "ciudadanía cultural", pueden consultarse los trabajos de Gundermann (1995, 1997 y 1998). Compartiendo muchos de sus conceptos e ideas, nos separamos de él en un punto: la relación entre ciudadanía política, social y cultural o étnica se sitúa en un plano más bien descriptivo, sin que se analicen los conflictos que estas formas de reconocimiento --en nuestra conceptualización-- plantean al interior de los pueblos indígenas y entre éstos y el o los Estados nacionales. Recuérdese que tanto los mapuches como los aymara se encuentran divididos por las fronteras de varios Estados nacionales (Argentina y Chile, en el primer caso; Perú, Bolivia y Chile, en el segundo). Esto constituiría un evidente obstáculo para la implementación de una ciudadanía ampliada por parte de los respectivos estados nacionales, así como un potencial foco de conflicto.
}

igualitario y la política de reconocimiento de las diferencias culturales, de las que hemos hablado en la primera parte del trabajo, aparecen como irreconciliables. O mejor, sólo bajo la forma de la autonomía política, bajo una nación mapuche, existiría la posibilidad de recuperar la dignidad individual perdida. En cualquier caso, prácticamente no encontramos nunca, salvo en el caso de Elicura Chihuailaf, una distinción entre los derechos de los mapuches como ciudadanos y como miembros de un grupo étnico. Obviamente, aquí está supuesta la necesidad de reconociliar ambos tipos de derechos, con lo que también se plantea el problema de cómo participar de un espacio ciudadano compartido con el resto de la sociedad chilena, o basado en el derecho igualitario, y un espacio propio de los mapuches como etnia, basado en derechos colectivos.

Ciertamente aquí habría que hacer muchas precisiones respecto a las diferentes posiciones. Sin embargo, la manera como se conceptualizan el pluralismo étnico y nacional no integra la reivindicación de un estado de derecho democrático con la exigencia de un respeto a la diversidad cultural.

\section{El Mercurio y la visión conservadora}

En general, El Mercurio denuncia que el Gobierno crea, genera, o por lo menos estimula el problema indígena con su política de discriminación positiva. No obstante parece olvidarse que la discriminación negativa que él mismo promueve (los mapuches no son un pueblo, o son sólo un sector dentro de los más pobres del país) también alienta el "conflicto étnico". No podemos dudar de las reacciones de molestia que deben provocar la lectura de El Mercurio entre los intelectuales mapuches; sería absurdo desconocer que es el vocero de una política fuertemente criticada por la "clase política" mapuche.

Pero la relación es más compleja, hay un efecto especular entre la intelectualidad mapuche y El Mercurio; ambos se necesitan, ambos juegan a través del otro a la profecía autocumplida. La argumentación mercurial confirma a los intelectuales mapuches lo que ellos siempre han pensado sobre los chilenos: el deseo de ser integrados a una nación que no les corresponde. Por otro lado, El Mercurio, al presentar y definir de forma tan negativa a determinados dirigentes mapuches, los ha transformado en verdaderos héroes locales. El caso de Aucán Huilcamán es paradigmático. Podría sostenerse que 
sin la mediación de la prensa y de la televisión huinca este dirigente no tendría el peso que hoy día tiene.

Si la nación es una "comunidad imaginaria" y esa comunidad es posible gracias a la escritura (Anderson 1993), uno podría sostener la visión de El Mercurio es, de algún modo, el negativo (en un sentido fotográfico) de esa comunidad imaginada que reconocemos como mapuche. Miles de ejemplos podrían traerse a colación, ya que se trata de una operación permanente. Unas familias se toman un predio, El Mercurio titula la noticia: "Mapuches se toman un fundo"; unas personas queman una camioneta, el título del suceso se transforma en "Violencia mapuche". Este es obviamente un ejercicio que promueve dicha comunidad; a los sujetos se le otorga una identidad y simultáneamente una colectividad: mapuche. Ahora bien, esa colectividad no es autoreferida, forma parte de otra mayor, a la cual subordinarse, la nación chilena.

Para El Mercurio ${ }^{58}$, los mapuches no son más que un "sector de la nación" (11-06-99), por tanto no pueden exigir ni más ni menos de lo que puede exigir cualquier otro:

"El artículo primero de la Carta Fundamental establece que es deber del Estado promover la integración armónica de todos los sectores de la nación --lo que incluye a los indígenas--, y asegurar el derecho de las personas --también los de los indigenas-- a participar con igualdad de oportunidades en la vida nacional" (El Mercurio 11-06-99).

58 Salvo que se indique lo contrario, todas las referencias son a su página editorial, que contiene lo medular de su visión. Sorprende su coherencia, cómo sus grandes lineamientos se mantienen inalterables a través del tiempo, y cómo su voz se prolonga en los voceros regionales (por ejemplo, en El Diario Austral de Temuco). No obstante, un mínimo de pluralismo es necesario: los otros cuerpos han dado cabida, aunque muy parcialmente a expresiones que contradicen o no siguen la línea editorial. Puede consultarse, p. e., La Revista de Libros N²54 del 13 de marzo de 1994 dedicada a "La poesía Mapuche Hoy", o el suplemento Artes y Letras del 7 de noviembre de 1999, que dedicó 4 páginas al tema mapuche. Aquí aparece un artículo de O. Contardo sobre el mapudungün, una reseña de R. Foerster y una entrevista a Bengoa. También debe considerarse el cuerpo $\mathrm{D}$, de Reportajes, que tuvo como tema central el conflicto mapuche el 28 de febrero y el 5 y de 12 de marzo de 1999; la segunda página de la Revista de Libros, donde aparecieron dos o tres referencias el año anterior, $\mathrm{y}$, por cierto, el cuerpo $\mathrm{C}$, con informaciones nacionales.
Esta es la clave de su argumento. Ahora bien, esto no significa que se desconozca el hecho que los mapuches no están plenamente integrados a la nación. Se lo admite y se plantea que lo que debe hacerse es incorporarlos. No obstante, la política de la Concertación ha producido el efecto contrario:

"En las postrimerías del segundo gobierno de la Concertación, es evidente que su política indigenista, sostenida durante la presente década contra todas las advertencias de la prudencia, arroja resultados desastrozos: no se ha logrado sacar a los presuntos beneficiarios de la extrema miseria ni se ha avanzado en su incorporación al resto de la nacionalidad chilena" (El Mercurio 15-04-99).

Más aún, la política del Gobierno habría estimulado el "temperamento separatista" de los mapuches, cuestión que se podría haber mitigado por la economía de libre mercado:

"La Ley Indígena asignó a los miembros de la etnias originarias una condición parecida a la de personas relativamente incapaces, carentes de la libre disposición de sus bienes. Ello los ha marginado de los beneficios de una economía libre y ha contribuido a su temperamento separatista" (El Mercurio 12-08-99).

En esta misma línea se puede situar la siguiente afirmación:

"Hasta que se inició el gobierno de la Concertación, el problema de los mapuches no era racial, sino de extrema pobreza. Debido a la política de aquélla, sin embargo, está transformándose en un problema seudorracial" (El Mercurio 16-03-99).

La línea editorial de El Mercurio es aquí vacilante, ya que no duda en designar a los mapuches como un sector diferente de la nación, empleando términos como "etnía", "etnias originarias", "indígenas" y mientras también afirma, tributaria de las categorías decimonónicas, que estamos enfrentados a un "conflicto racial". En cualquier caso, muestra que los mapuches son un grupo diferente, no plenamente homologable al resto de los chilenos.

Demos un paso más. Los juicios sobre el "temperamento" de los mapuches permiten bosquejar una suerte de antropología mercurial sobre los mapuches, donde siempre aparecen como pasivos, 
y si son activos es por culpa de alguien externo a ellos: del gobierno, de la izquierda marxista, de los ecologistas. Influidas o intervenidas por estos agentes, las acciones de los mapuches se convierten en una amenaza seria al orden político y jurídico del país:

“...el Gobierno ha continuado llevando adelante la misma política que tales alarmantes resultados ha tenido; esto es, comprar a particulares, con recursos de los contribuyentes, tierras exigidas por los ocupantes o que amenazan serlo, para entregárselas a éstos. Como era obvio. apenas así lo hizo respecto de dos comunidades, en Traiguén y Purén, se han multiplicado las ocupaciones de predios en Malleco y Arauco. Apoyadas por dos entidades denominadas Consejo de Todas las Tierras --nombre de suyo elocuente-- y Coordinadora de Comunidades Mapuches, numerosos grupos se han declarado 'en alerta permanente', y fijan plazos al Ministerio de Bienes Nacionales para que se les 'devuelvan'sus tierras, anunciando que, de no recibir respuestas, entenderán que el Estado acoge su existencia.

Este cuadro desafía no sólo la Ley de Seguridad del Estado, sino que todo el marco constitucional y legal chileno" (El Mercurio 3-05-99).

La intervención externa en los "conflictos raciales" es un asunto que preocupa enormente a El Mercurio. Su tematización evoca argumentos que estuvieron vigentes en el siglo pasado, durante el período de la ocupación de la Araucanía, por ejemplo, con la aparición de Orellie Antoine, el autoproclamado "Rey de Araucanía, Patagonia y Pampas":

"Ningún inversionista arriesgará recursos en la zona perjudicada hasta que se vuelva a respetar el Estado de Derecho y se alcance una paciflcación que dé sentido al derecho de propiedad...

Los costos crecerán todavía más cuando a los robos y heridos se sumen los muertos que comenzarán a aparecer al hacerse más agudo el conflicto. Ya se habla de la existencia de grupos radicalizados y para nadie es un misterio que variadas organizaciones internacionales pueden financiar conflictos de envergadura. El país podría llegar a tener una especie de guerrilla con el apoyo y la simpatía de muchos chilenos y extranjeros, impresionados por las lamentables condiciones de vida de los indíge- nas...

Los conflictos raciales no deben ser alentados, porque pueden llevar a extremos como los recientemente vistos en la ex Yugoslavia, donde, además de las luchas internas, se ha producido una abierta intervención foránea" (El Mercurio 18-12-99, La Semana Económica).

La imaginería mercurial es terrible: el futuro será de violencia y de muerte, nuestra realidad se hará equivalente a la de la ex Yugoslavia o la del México de Chiapas (guerrilla indígena). La responsabilidad de que esto no se produzca es que el Gobierno enmiende su política hacia los mapuches. No existe ninguna duda de que las recuperaciones de tierras hechas por los mapuches carecen "de asidero jurídico... y se relacionan con un plan de agitación política de envergadura con que la izquierda marxista aspira lograr determinadas ventajas" (El Mercurio 13-06-99). De este modo, estaríamos frente a un escenario donde el radicalismo político-racial o incluso el terrorismo y la delicuencia se revisten bajo el falso ropaje del "conflicto étnico":

"En la IX Región se ha llegado a un estado de casi completa impotencia del aparato de defensa legal contra el delito, todo bajo la apariencia, que no es real, de un conflicto étnico con personas de origen mapuche" (El Mercurio 5-08-99).

De allí que El Mercurio sostenga que la solución de los problemas mapuches pasa por la intervención del Estado y su integración a él:

"Los hechos conocidos hasta el momento llevan a concluir que la solución al problema mapuche no pasa por la vía fácil de acceder a sus demandas, como ocurre hasta ahora. Ellas, en efecto, pueden ampliarse y mantenerse en el tiempo como resultado de un plan bien meditado. Por el contrario, ella pasa, en lo esencial, por el respeto al Estado de Derecho y por la aplicación de una política que se enmarque en el mismo y que busque una efectiva integración indígena a la institucionalidad vigente" (El Mercurio 30-05-99).

El Mercurio reproduce así la vieja tradición portaliana, el orden institucional trascendentalizado como "peso de la noche". El reconocimiento constitucional como pueblo a los mapuches es entonces una locura, ya que de aprobarse "existirán dos na- 
ciones, la de los pueblos indígenas y la del resto de los habitantes del país" (El Mercurio 11-06-99). Con ello se desplomarían la unidad y el orden del país. En la misma dirección, el Gobierno y el Estado chileno deben desestimar lo relativo a la deuda histórica con los mapuche por ser esta "(una) tesis...discutible en rigor científico" (El Mercurio 11-06-99). Se hace un llamado al Gobierno a rectificar su política hacia los mapuches, buscar su integración, en especial al mercado ya que él permite la movilidad, "desvincularlos de la tierra" 59 ; y hacer prevalecer el estado de derecho en la región. Si se nos permite añadir una observación crítica, se trataría, de aplicarse, de una política de asimilación forzosa vía la combinación de estrategias represivas y de mercado. Las propuestas de El Mercurio crearían precisamente el escenario de agudos conflictos étnicos que busca evitarse.

Llevado a su extremo, este razonamiento significa que la sola preservación de la cultura mapuche o su no integración plena son una amenaza de ruptura a la unidad de la nación chilena; por ende, una amenaza también al orden social, económico y político. Las movilizaciones mapuches, inspiradas en concepciones de índole radical y fundamentalista e instigadas por la izquierda marxista, no harían sino corroborar esta percepción.

La concepción de nación que está en juego es, obviamente, la de una Volksnation esencializada. ¿Qué sucede, entonces, con la amenaza de la división, la fragmentación nacional? Aquí puede resultar provechoso avanzar un poco en la interpretación, retomando los conceptos de Carl Schmitt, brillante jurista y teórico político alemán.

El Mercurio y los sectores conservadores que representa conciben la relación con los mapuches a la manera de la lógica amigo/enemigo de Schmitt. Siempre está abierta la posibilidad de un conflicto en defensa de la unidad política del Estado nacional:

"El [enemigo] es justamente el otro, el extraño, y

59 El Mercurio critica duramente a los gobiernos de la Concertación por haber fomentado una política de "vincularlos a la tierra", en la medida que al "mantener a los mapuches atados a la tierra, como a los siervos de la gleba medieval, les quitará movilidad y les limitará la posibilidad de hacer otros trabajos en la región o fuera de ella, que es una de las verdaderas soluciones para salir de la extrema pobreza" (1812-1999). su esencia queda definida suficientemente por ser algo distinto y extraño en un sentido existencial especialmente intenso, de modo que en un caso extremo sean posibles los conflictos con él. Conflictos que no pueden ser decididos por una normativa general anterior y apropiada al caso, ni tampoco por el juicio de un tercero 'no incluido' (unbeteiligt) y por tanto "imparcial"' (Schmitt 1932: 27). ${ }^{60}$

Estos conflictos que, como vemos, no pueden ser resueltos sobre una base normativa ni por la intervención de un mediador, pueden llegar a tener implicaciones extremas:

"Los conceptos de amigo, enemigo y lucha adquieren su verdadero sentido en la medida que se refieren a, y conservan la posibilidad efectiva del exterminio físico" (Schmitt 1932: 33) ${ }^{61}$

Un estado democrático se funda en la igualdad, pero ésta es una igualdad política, que se dirige hacia dentro del Estado y no hacia fuera ni a los extranjeros. Por ende, debe distinguirse de la idea de una igualdad de todos los hombres (Menschengleichkeit) (Schmitt 1928: 226). Ahora bien, en el caso de una democracia fundada en el principio de la nacionalidad, una "democracia nacional", la unidad del Estado sólo puede constituirse y mantenerse, en la medida en que Estado y nación sean uno, o sea, en tanto exista una homogeneidad étnica o nacional:

"Un estado democrático que cumple con los requisitos de homogeneidad (Gleichartigkeit) nacional de sus ciudadanos, concuerda con el llamado principio de nacionalidad, de acuerdo al cual una nación forma un Estado, y un Estado, una nación" (Schmitt 1928: 231) (22 $^{2}$

60 Hay traducción al español: Schmitt (1984). Para un análisis crítico de Schmitt, véase: Habermas (1987) y Hinkelammert (1987b). Las interpretaciones más recientes han mostrado el núcleo teológico de la obra de Schmitt. Al respecto, véase: Lilla (1997), que se basa fundamentalmente en el trabajo de Meier (1994).

61 En este caso, nos parece apropiado incluir el texto original, de díficil traducción: "Die Begriffe Freund. Feind und Kampf erhalten ihren realen Sinn dadurch, dab sie insbesondere auf die reale Moglichkeit der physichen Totung Bezug haben und behalten".

62 "Un Estado nacional homógeneo --agrega Schmitt-- aparece entonces como algo normal; un Estado al que le falta esta homogeneidad, tiene algo anormal, que amenaza la paz" (Schmitt 1928: 231). Haber notado la importancia del "principio de nacionalidad" en Schmitt, lo debemos a Habermas (1996b: 166-169, 1999: 113 y 120-121). 
En caso que un Estado esté compuesto de diferentes naciones o minorías nacionales, existen, según Schmitt, sólo dos alternativas: su separación o asimilación pacífica a la "nación dominante"; o bien la aplicación de un método más rápido y violento, "la eliminación (Beseitigung) de la parte extraña a través de la represión, la evacuación de la población heterógenea y otros métodos radicales similares". Dichos métodos pueden incluir el control de la inmigración de extranjeros a través de la legislación o la segregación espacial, esto es, la construcción de protectorados, colonias, etc (Schmitt 1928: 132). Schmitt es explícito en que esto es una consecuencia del principio de homogeneidad democrática, que se opone a la idea liberal de la igualdad y libertad de cada individuo con respecto a cualquier otro.

Podría pensarse que, en nuestro caso, la identidad entre Estado y nación preconizada por $\mathrm{Schmitt} \mathrm{ocul-}$ ta una asimetría, y es la primacía del Estado sobre la nación. En efecto, según la historiografía conservadora, la nación chilena es un resultado de la acción del Estado chileno a través de las guerras. Góngora ha sistematizado esta concepción de manera ejemplar en su trabajo sobre el Estado en Chile. ${ }^{63}$ Pero esto no supone mayor problema para esta visión. La acción del Estado ha creado una conciencia nacional sobre la base de una unidad cultural anterior. ${ }^{64}$ Por ende, como obra suya, el Estado tiene que protegerla y preservarla contra toda amenaza interna o externa.

Obviamente aquí no pretendemos que la doctrina jurídica de Schmitt sirva de inspiración directa a los conservadores chilenos y a El Mercurio. ${ }^{65}$ Más bien

63 Para Góngora, "La nacionalidad chilena ha sido formada por un Estado que ha antecedido a ella ... A partir de las guerras de Independencia, y luego de las sucesivas guerras victoriosas del siglo XIX, se ha ido constituyendo un sentimiento y una conciencia propiamente 'nacionales', la 'chilenidad'”, Y aunque Góngora señala la importancia de otros elementos "puestos por el Estado", como los símbolos patrios, reitera que "son las guerras defensivas u ofensivas las que han constituido el motor principal". Esto debe ligarse, en todo caso, con la concepción portaliana de Estado, autoritaria y centralista, cuya decadencia durante el período parlamentario significa también la crítica radical al "ideal patriótico guerrero, principio inviolable para el siglo XIX chileno" (Góngora 1981: 37 38 y 126). Por otro lado la tesis de Góngora se refuerza con un argumento que desvaloriza a los pueblos "originarios" de Chile, al ser éstos incapaces de prefigurar la nación: "La nacionalidad chilena ha sido formada por un Estado que ha antedicho a ella, a semejanza, en esto, de la Argentina; y a nos interesa mostrar la lógica de este tipo de discursos, lógica que Schmitt llevó hasta sus últimas consecuencias: la posibilidad del sometimiento violento e inclusive la destrucción del extraño, en este caso, del extraño a la nación, entendida ésta como unidad substantiva. ${ }^{66} \mathrm{Y}$ sin duda, no puede resultar entonces mera coincidencia que el pensamiento de Góngora sobre este tema tenga una impronta de Schmitt.

\section{La postura del Gobierno y de la Concertación ${ }^{67}$}

Si para El Mercurio la actual Constitución puede

diferencia de México y del Perú, donde grandes culturas autóctonas prefiguraron los Virreinatos y las Repúblicas" (Góngora 1981: 37). Este argumento ya se encuentra en Eyzaguirre, como puede verse en la nota siguiente.

64 "Ya en los tres siglos anteriores (a la Independencia R.F. y J.I.V) el continuo oleaje de sangre española había creado una raza homógenea en la que no se integró el belicoso araucano del sur del Bío-Bío" (Eyzaguirre 1967: 15). Obviamente, los mapuches. llamados por Eyzaguirre "araucanos", no forman parte de la "raza chilena", al menos hasta el siglo XIX. Y la idea de "patria" no podía surgir en ellos ni en los demás grupos indígenas que existían en el país a la llegada de los conquistadores, dice en otro texto. Su "mente primaria" sólo podía concebir "una imagen circunscrita del mundo" (Eyzaguirre 1948: 13).

65 Lo que no excluye, que, de hecho, en el pensamiento político de la derecha chilena exista una influencia de Schmitt, sobre todo entre los juristas. Renato Cristi rastrea la presencia de Schmitt en el historiador Mario Góngora (Cristi 1992: 144145 y 155) así como en Jaime Guzmán, y, a través de él, en la Constitución de 1980 (Cristi 2000). Particularmente ilustrativa respecto al caso que nos ocupa es la afirmación de Cristi, que Góngora "presenta al Estado como la fuerza más dinámica en el desarrollo de Chile como nación". Lo que Barrington Moore llamó "modernización conservadora" es interpretado por Góngora "de un modo emparentado con Spengler y Carl Schmitt. Así, el nacionalismo surge y se mantiene vivo en el Chile republicano como resultado de una mentalidad beligerante. Esta constituye el legado de la era colonial cuya interminable guerra contra la resistencia mapuche determina todos los aspectos de la vida" (Cristi 1992: 144).

66 Esta última no sería ya una situación de dominación propiamente tal, ya que, como implícitamente reconoce Walzer, la dominación estatal puede significar el sometimiento de un pueblo, pero la expulsión y el genocidio eliminan inclusive la condición para que el sometimiento exista, y ésta es la existencia física del dominado "Debo subrayar que mi objeto de estudio es la convivencia de distintos grupos bajo dominio estatal. Mientras el sometimiento (Unterdrückung) es una forma concebible de convivencia, la expulsión y el genocidio claramente no lo son" (Walzer, 1996: 101).

67 Cronológicamente, nuestro análisis llega fundamentalmente hasta marzo del 2000 , fecha en la que concluyó la primera versión de este trabajo. Posteriormente (febrero de 2001), hemos añadido algunos comentarios sobre los acontecimientos posteriores, pero sin pretender hacer un análisis propiamente dicho. 
ser utilizada para "velar por la protección y el desarrollo de las etnias nativas", el gobierno piensa lo contrario, que debe ser modificada. En las postrimerías de su gobierno, Frei habló en agosto de 1999 de "reforzar la nueva relación con los pueblos indígenas" que se habría iniciado con el pacto de Nueva Imperial en 1989:

"como una forma de reforzar la nueva relación con los pueblos indígenas, se despachó al Congreso Nacional la ratificación del Convenio 169 de la OIT y la reforma a la Constitución Política del Estado. Ambos instrumentos, de rango superior, buscan reconocer y valorar la existencia de las culturas indigenas que integran nuestra sociedad" (Frei 1999a).

El problema de esta propuesta es doble: su viabilidad y su traductibilidad. ${ }^{68}$ La tramitación ante el Parlamento de ambas reformas fracasó por segunda vez en octubre del año anterior (la primera fue bajo la presidencia de Patricio Aylwin), al ser rechazada por la Cámara de Diputados. Inclusive, sólo 44 de los 70 diputados de la Concertación apoyaron el proyecto.

En cuanto a la traductibilidad, se trata del alcance que tiene el reconocimiento como pueblo. Si el escenario fuera el mismo que se ha dado en los conflictos de Ralco, de Lumaco-Traiguén y en los Diálogos Comunales (marzo-julio de 1999) las posibilidades de encuentro o coincidencia entre las organizaciones mapuches y el gobierno serían pocas. Se ha optado generalmente por tratar sólo con las familias o comunidades directamente afectadas, desconociendo las "organizaciones indígenas de carácter territorial" y evitando abordar temáticas como los derechos históricos sobre tierras y territorios, compensación por impactos ambientales y otras (Aylwin 2000). En el caso de los Diálogos Comunales hubo, a nuestro juicio, una clara estrategia de fragmentar las demandas étnicas y etnonacionales

68 Siguiendo a Marcuse (1966: 133), consideramos que las ideas políticas -en este caso las ideas del Gobierno de la Concertación relativas al tema mapuche- deben ser analizadas no sólo en su coherencia interna, sino también en relación con las "condiciones existentes (políticas, económicas, intelectuales) que determinan la posibilidad de su realización. A menos que este factor logre surtir efecto sobre la idea, permanece solamente al nivel de discurso, publicidad, propaganda -a lo sumo de una afirmación de intenciones. Es responsabilidad del estudioso tomar todo esto en serio, es decir, ir más allá de las palabras o mejor, permanecer más acá de las mismas, en el universo dado de los poderes, capacidades, tendencias, que definen su contenido". mapuches, dándole además mayor cabida a las demandas campesinas, que si bien existen, no tienen necesariamente el lugar de preponderancia que se les dio luego de los Diálogos Comunales.

Por otro lado, el gobierno sabe que hay un trasfondo histórico en los vínculos entre ambos pueblos, esta realidad es tematizada bajo la imagen de "la deuda histórica". El entonces Ministro de Planificación, Germán Quintana, encargado de conducir los Diálogos Comunales, lo expresó así:

"Es evidente que no podemos retroceder en el tiempo. Tenemos que partir del presente, de donde estamos, reconociendo las injusticias, la deuda histórica que los huincas tenemos con el pueblo mapuche y ahi reparar" (Quintana 1999: 26).

Aquí se deja traslucir la conciencia que el problema mapuche tiene una dimensión muy distinta a la de otros grupos marginales o pobres, y que no podría reducirse a su condición económica campesina. Sin embargo, de acuerdo a Quintana, el resultado de los Diálogos Comunales habría sido que las "demandas efectivas" de los mapuches son, en primer lugar, de infraestructura y servicios; luego económico-productivas y sólo en tercer lugar "sociopolíticas", de "asignación de tierras" y de "inserción cultural" (Quintana 1999: 26). ${ }^{69}$ Lógicamente, deberían privilegiarse precisamente las demandas campesinas.

Además, la idea de una "deuda histórica" con el pueblo mapuche, que podría abrir la puerta a una política de reconocimiento étnico, queda a un nivel meramente discursivo o bien se restringe a una dimensión: la compra de terrenos. Así se comprueba en el discurso del entonces Presidente Frei frente a los dirigentes mapuches, en agosto de 1999, donde señala una de las vías para encarar la deuda:

“El problema del acceso a las tierras por parte de los indigenas y sus comunidades, refleja de modo particularmente significativo la deuda asumida con los chilenos indígenas. Como lo señalé ante el Congreso Pleno el pasado 21 de mayo, hubo en Chile una larga historia de ocupación y de apropiación de territorios indígenas. Es por ello que hemos tomado las medidas que nos permitirán tener resuel-

69 Véase también: La Tercera del 4, 5 y 6 de agosto. Las noticias pueden ser consultadas a través de la página web del diario: www.tercera,cl, en la sección correspondiente al "Conflicto Indígena". 
to en no más de dos años el conjunto de demandas pendientes de tierras formalizadas y aprobadas por el Consejo de la Corporación Nacional de Desarrollo Indígena en 1997, destinando para ese efecto montos crecientes de recursos.

"Además, he dispuesto el estudio de un nuevo mecanismo para la adquisición futura de tierras, que supere las insuficiencias del actual procedimiento. De este modo estamos respondiendo con responsabilidad y con una mirada de país, a las aspiraciones de nuestros compatriotas indígenas" (Frei 1999a).

Para el gobierno, entonces, el tema del reconocimiento de los mapuches tiene una carga que puede ser superada en el tiempo, lo que permitiría que al fin ellos pudieran gozar plenamente su calidad de ciudadanos ("compatriotas indígenas"). Se requiere de una sociedad tolerante y respetuosa con la diferencia, una sociedad pluralista que respete y valore la diversidad. No resulta extraño que el acto final de clausura de los Diálogos Comunales terminara en Santiago con la firma del "Pacto por el Respeto Ciudadano". ${ }^{70}$ Se nos dice que con "este Pacto, se sella el compromiso de:

"1. Desarrollar una sociedad que sea cada dia el espacio fecundo para que cada individuo o comunidad pueda desarrollar con orgullo su identidad cultural en armonía con los otros; donde la paz, el respeto y la celebración de la diversidad erradiquen la ignorancia, la violencia y la discriminación.

"2. Promover una cultura y una educación que valoren la expresión de las identidades particulares, el respeto de las comunidades diferentes y la consideración de los demás, el aprendizaje sobre los pueblos indígenas, el florecimiento del potencial latente en cada persona y grupo que habita este suelo.

"3. Impulsar un modelo de desarrollo que contemple e integre la diversidad de nuestras costumbres, modos de vida y deseos de futuro; buscar siempre el respeto y el diálogo la solución de intereses a veces contrapuestos y en la equidad, una guía orientadora.

"4. Velar por el perfeccionamiento de un orden jurídico que respalde y proteja los derechos y responsabilidades de los ciudadanos, eliminando y sancionando toda forma de discriminación e intoleran- cia, y que cautele el cumplimiento de las leyes que favorecen el respeto de la diversidad.

"5. Promover formas de participación que permitan la expresión de las necesidades y ejercicio de los derechos y responsabilidades de cada ciudadano, comunidad o pueblo indígena, haciéndolo protagonista de su identidad y proyectos en el respeto de los demás seres humanos.

"El ejercicio de una convivencia basada en estos compromisos nos hará posible construir este espacio de fraternidad llamado Chile, donde la riqueza de la diversidad de las expresiones culturales, espirituales y religiosas sean motivo de orgullo para todos y garantía de mejor vida para las generaciones futuras" (Frei 1999b).

A primera vista, esta postura del Gobierno resulta sumamente atrayente y consonante en gran medida con una política de reconocimiento de las diferencias. Sin embargo, ella adolece de dos limitaciones básicas.

En primer término, enuncia una serie de propósitos y metas, con las cuales díficilmente podría no coincidirse, pero no establece el modo cómo cumplirlas ni tampoco cómo los propios pueblos indígenas podrían tomar parte en dicha realización. La participación de dichos pueblos no es definida claramente. o se hace en términos muy ambiguios y generales, lo que permite que se califique --indirecta o directamente-- a quienes inician movilizaciones en pos de la satisfacción de sus demandas, como opuestos al diálogo. Al respecto las palabras del ex Ministro Quintana son ejemplificadoras al insistir en que los diálogos comunales son "el símbolo de una relación" entre el "poder político" y "los representantes de las comunidades étnicas para lograr alianzas y acuerdos tendientes a efectuar cambios institucionales y productivos", pues allí reside "la clave del éxito". Se trata de una verdadera creatio ex nihilo pues los diálo-

\footnotetext{
70 Esta dimensión ciudadana es omitida por Naguil (1999: 36) cuando asevera que "el Estado y en particular el gobierno, quiere resolver la situación mapuche, y en particular las reivindicaciones de las comunidades, mediante el aumento de los recursos en las instituciones responsables de tratar la problemática, sin querer entender aún que la solución de estos conflictos desborda estos restringidos aspectos y tiene que ver con un cambio total de los enfoques políticos, los instrumentos y las medidas a adoptar".
} 
gos realizados con los mapuches "deberían ser un antecedente fecundo para la convivencia de estas comunidades que recién empiezan a conocerse" (Quintana 1999: 25). Aquí se omite en principio toda consideración respecto a las políticas de gobierno desde 1990, o incluso antes, desde 1989 con el Acta de Nueva Imperial. Recién al final del artículo se habla de la continuidad entre dicha Acta y el Pacto de Respeto Ciudadano. Obviamente, no se plantea porqué ni cómo se ha producido el desencuentro entre el Gobierno y los pueblos indígenas, sobre todo sus organizaciones, qué es lo que ha hecho necesario un nuevo acuerdo.

Por otro lado, afirma Quintana, con este proceso de diálogo "se ha impuesto una vez más el sistema democrático" e incluso se ha inaugurado un "nuevo trato" --expresión que después recogerá el actual Presidente Lagos-- entre "la sociedad chilena y las minorías en general". Y el diálogo, a la manera como él lo entiende, es la única vía posible de solución de las demandas mapuches. Lo opuesto es "la simplificación, la caricaturización fácil, la agresión”, y "Chile sabe a dónde conducen esas intolerancias. La violencia sólo contribuye a levantar muros entre ciudadanos, a agrandar las brechas" (Quintana 1999: 26). ¿Quiénes ejercen dicha violencia?: los que están contra el diálogo. Quintana no lo dice explícitamente, pero hay una referencia a los movimientos mapuches que realizan tomas o se niegan a tomar parte en las instancias de negociación erigidas por el Gobierno. Se trata de una oposición entre alternativas excluyentes: democracia/diálogo versus autoritarismo/violencia.

Al respecto vale la pena recordar lo que Marcuse diagnosticó una vez como un vaciamiento de las ideas en el discurso político, que opera a través de una "asimilación de lo ideal con lo real" (Marcuse 1964: 57, 1965: 87). Todos los términos del discurso de Quintana así como la Declaración del Pacto son, efectivamente, expresiones ideales, pero lamentablemente vacías o sin sentido si no se les da un contenido más concreto y definido ni se ponen los medios de realización de ellas. Su única realización es la que lleva a cabo el gobierno: lo ideal se confunde con lo posible y éste con lo real. Se trata de una peculiar forma de utopismo democrático, que no renuncia del todo a enunciar alguna forma ideal de convivencia futura, pero restringe su viabilidad a las condiciones presentes. En dicha visión, la resolución democrática de los conflictos es desvinculada de "toda historia concreta" y de "la propia discusión de las condiciones económico-sociales de la organización democrática del poder político" (Hinkelammert 1987a: 226). La democracia aparece como "un paraíso prometido de simple diálogo, donde las divergencias son de opinión y no de intereses"; no comprenden las cuestiones económicas y sociales, y, en este caso, agregaríamos también las cuestiones culturales relativas a las identidades étnicas y/o etnonacionales. Los movimientos sociales que hacen dichas reivindicaciones son, por tanto,una amenaza o un peligro "para la democracia" (Hinkelammert 1987a: 226).

En segundo término, no hay una consideración respecto a cómo dentro del propio Estado se produce y reproduce la dominación étnica, y en consecuencia, la necesidad de introducir modificaciones substantivas dentro de su organización y estructura jurídico-institucional a fin de reconocer y dar espacio a las formas de organización de los pueblos indígenas. En otras palabras, se ignora o minimiza la dimensión de poder sobre los grupos étnicos que está presente dentro de la propia institucionalidad estatal. Aquí tiene sentido la caracterización de Kymlicka (1996) o Smith (1997) de la dominación de una "mayoría nacional" y una "minoría nacional" y que no son consideradas o percibidas por posturas como las del Gobierno, por una naturalización de los vínculos sociales.

\section{Conclusiones}

Queremos ahora hacer algunas reflexiones amplias sobre el proceso que hemos descrito. Las concepciones sobre la política de reconocimiento son diversas y complejas. Tenemos al menos tres posiciones: la de los mapuches, la del Gobierno y la del sector conservador, expresada en El Mercurio. Como hemos visto, existen pocos puntos en común entre ellas. El sentido que se le pretende dar al reconocimiento es muy diverso. En el caso mapuche, se busca con cada vez mayor fuerza un reconocimiento etnonacional, subordinando las demandas étnicas y campesinas (aunque éstas continuan estando presentes). En el del Gobierno, el reconocimiento es étnico y ciudadano, aunque con tendencias a retomar una política campesinista. Para los conservadores, en cambio, el único reconocimiento posible es el que se ofrece a todos los demás chilenos, insistiéndose además en la necesidad de restaurar el "estado de derecho", y llevar a cabo la deseada pero 
nunca concluida integración de los mapuches a la nación chilena.

Sin embargo, estas diferencias ocultan una similitud, una concepción compartida que consideramos un obstáculo para la conformación de un debate amplio sobre el carácter de la nación chilena y su pertenencia a ella de los grupos indígenas, especialmente los mapuches. Se trata de la presencia de una visión de la nación como nación-pueblo, como una comunidad natural, cuyos vínculos no son problemáticos, sino que están dados y definidos.

Díficilmente el Gobierno podrá dar a la dimensión ciudadana la relevancia que le atribuye mientras no problematice la definición tradicional de la nación chilena como unitaria y homógenea culturalmente. El ejercicio pleno de los derechos ciudadanos y la participación no sólo se encuentran hoy limitados por un sistema político e institucional de carácter no plenamente democrático y un modelo económico que genera desintegración social y exclusiones, sino también por una configuración del Estado-nación que no deja suficientes espacios a la diversidad étnica y cultural. Lo dicho es aún más claro en el caso de El Mercurio, que sustenta a la vez una defensa irrestricta de la política económica neoliberal, de la herencia autoritaria del régimen militar y una concepción de la nación como unidad homógenea, incluso racial.

Para los mapuches, como todos los demás pueblos indígenas que habitan este país, el desarrollo de la ciudadanía está intímamente ligado al desarrollo y respeto de su cultura y formas de organización social, política y económica. ${ }^{71}$ Mientras no se plantee la necesidad de un amplio debate para redefinir el carácter de la pertenencia "nacional" de los grupos indígenas, poco podrá avanzarse en la solución de los conflictos étnicos que han marcado la relación de la sociedad chilena con los mapuches en los últimos años. Si hay un círculo vicioso, éste no consiste en acoger favorablemente demandas étnicas para, de ese modo, contribuir a su progresivo aumento e irresolución, sino en la desconsideración de las exigencias de reconocimiento realizadas por las organizaciones y comunidades mapuches, exigencias que

71 Remitimos aquí a los trabajos de Gundermann (1995, 1997 y 1998).

$72 \mathrm{Al}$ respecto, véase también el artículo de Aylwin (2000), uno de los pocos que se aventuran en el díficil camino de las propuestas sobre la resolución de los conflictos étnicos. hoy tienen en buena medida un contenido etnonacional.

Indiscutiblemente, no nos concierne indicar pasos concretos a seguir para alcanzar esta meta, pero al menos podemos señalar algunas condiciones que harían posible un diálogo de este tipo y los óbstaculos que existen actualmente. ${ }^{72}$ En relación a las condiciones, creemos que la realización de un diálogo efectivo requiere un tratamiento más integral de los diversos puntos y temas de conflicto, en el que puedan participar no sólo las comunidades afectadas, sino también las organizaciones y los líderes representativos. Por otro lado, dicho diálogo no puede darse sobre la base de una situación de hecho que los mapuches deben aceptar, por ejemplo, la ejecución de un megaproyecto en marcha. Por el contrario, deberían hacerse sin presiones de ningún tipo y bajo la premisa de una igualdad de los participantes. En tercer término, debe llevarse a cabo una discusión seria sobre el carácter de la "nación" chilena y el lugar que han tenido y deben tener en ellas los diversos pueblos indígenas del país, dando pie al reconocimiento de las diversidades culturales y los derechos colectivos. Por último, nos parece fundamental que exista una voluntad de implementar cambios en la estructura misma del Estado chileno, que permita que haya una mayor participación de los mapuches en las decisiones sobre sus propios asuntos. En otras palabras, que haya un aumento efectivo del poder y la autonomía indígena y se reduzca o minimice la dominación estatal.

En cuanto a los obstáculos, muchos de ellos han sido mencionados indirectamente antes. Habría que agregar algunos que comprometen al propio movimiento indígena. También de parte de éste, no sólo del sector conservador y del Gobierno (aunque en tensión con la idea de reconocimiento étnico y ciudadano), se formula una concepción sustancializada de la nación, tal como hemos mostrado en las páginas anteriores. La idea de recuperación de la nación mapuche y su territorio, independientemente de su viabilidad política, indica una clara separación entre la sociedad chilena y la sociedad mapuche, con las consecuencias del caso. No sólo se trata de autonomía, como señala Bengoa (1997; 1999a y 1999b), sino de independencia territorial y nacional. Nos parece que los planteamientos de intelectuales mapuches como Chihuailaf, de indigenistas como Bengoa y Aylwin, así como los aportes de Taylor y Habermas sugieren una posibilidad diferente, repen- 
sar la relación de pertenencia nacional sin dejar por ello de lado la legítima exigencia de respeto a la diversidad. La integración nacional no necesariamente debe ir de la mano con la opresión étnica y el falso reconocimiento. Si se acepta esto, entonces también puede pensarse en una lucha por el reconocimiento que signifique un proceso de aprendizaje no sólo para los mapuches y demás pueblos indígenas, sino también para los propios chilenos. En este sentido pueden entenderse las propuestas de Chihuailaf y del mismo Consejo en algunos documentos. Indiscutiblemente, como analistas del problema, no pretendemos de ninguna forma decir cuáles deben ser las metas del movimiento mapuche. Este se da y seguirá dándose aquellas que considere más apropiadas. Pero sí creemos posible indicar al menos algunos caminos de diálogo y acuerdo (tan libre de coacciones como sea posible) entre dicho movimiento, el gobierno y la sociedad chilena, que permitan sustentar una utopía realista ${ }^{73}$ de una con- vivencia armónica entre las distintas culturas, etnias y poblaciones de Chile.

\section{Agradecimientos}

Agradecemos a Hans Gundermann y Jorge Vergara Estévez sus aportes y comentarios en las muchas conversaciones sobre estos temas. Igualmente a Aldo Mascareño, Roberto Hozven y Angel Oquendo por sus críticas y sugerencias. Todas las traducciones de citas de textos en alemán o inglés han sido realizadas por nosotros, con la amable colaboración de Leonor Quinteros, a quien hacemos presente también nuestros agradecimientos. A Haroldo Quinteros agradecemos la traducción del resumen al inglés.

73 " $[\mathrm{N}]$ o se hubiera conseguido nunca lo posible, si en el mundo no se hubiese recurrido siempre a lo imposible", dice Max Weber al final de su famosa conferencia "La política como vocación" (Weber 1919: 82).

\section{BIBLIOGRAFIA}

AMERICA INDIGENA, 1979. Surgimiento de una conciencia étnica (Editorial). América Indígena, Vol. XXXIX, $\mathrm{N}^{\circ} 3$, México, pp. 433-448.

ANDERSON, B., 1993. Comunidades imaginadas, FCE, México.

ANTILEO, A., 1999. Las forestales tendrán que irse de nuestro territorio (Entrevista), en: El Rodriguista, Año XV, separata especial, mayo de 1999, Santiago, pp. 1-8.

ARAVENA, A, 2000. Derecho consuetudinario y costumbre indígena. La consideración de la costumbre como atenuante o eximente de responsabilidad penal: informe pericial. XII Congreso Internacional. Derecho consuetudinario y pluralismo legal: desafíos en el tercer milenio ( 2 Tomos), Tomo I, Universidad de Chile-Universidad de Tarapacá, sin ciudad, sin fecha, pp. 146-153.

ARMIÑO, M., 1980. Prólogo a: Rousseau, Jean Jacques, Del contrato social//Discurso sobre las ciencias y las artes/Discurso sobre el origen de la desigualdad entre los hombres, Alianza Editorial, Madrid, pp. I-XIV.

AUKIN WALLMAPU NGULAM, 1997. El pueblo mapuche su territorio sus derechos. Impreso en los Talleres de Impresos Kolping, Temuco.

AYLWIN, J., 1998. Indigenous Peoples Rights in Chile: Progresses and Contradictions in a Context of Economic Globalization. Ponencia presentada al XXVIII Congreso de Calacs, Simon Fraser University, Vancouver, B.C., 19 y 21 de marzo de 1998. Fundación Rehue: http://www.xs4all.nl/ $\sim$ rehue/art/aylla.html.

AYLWIN, J., 2000. Los conflictos en el territorio mapuche: antecedentes y perspectivas. Fundación Rehue: http:// www.xs4all.nl/ rehue/art/aylla.html. Publicado originalmente en: Perspectivas, Vol. 3, N², 2000, Universidad de Chile, Santiago.

AYLWIN, P., 1990. Discurso del Presidente de la República con motivo del Acto de la Comisión Especial de Pueblos Indígenas. Nütram, Año VI, N², Santiago, pp. 43-46.

---- 1991. Discurso de S.E. el Presidente de la República, Don Patricio Aylwin Azócar, en clausura del Congreso Nacional de Pueblos Indígenas (Temuco, 18 de enero de 1991). Nütram, Año VII, No ${ }^{\circ}$, Santiago, pp. 3-9.

BACHRACH, P, 1967. Crítica a la teoría elitista de la democracia, Ed. Amorrtu, Buenos Aires, 1973.

BARRERA, A., 1999. El grito mapuche (una historia inconclusa), Grijalbo, Santiago.

BECK, U., 1996. Wie aus Nachbarn Juden werden: Zur politischen Konstruktion des Fremden in der reflexiven Moderne. Miller, Max y Soeffner, Hans-Georg (Eds.) Modernitât und Barbarei, Suhrkamp, Francfort del Meno, págs. 318-343. Traducción al inglés: How neighbors become Jews: The political construction of the stranger in a age of reflexive modemity. Constellations Vol. 2, No 3: 378, 396, 1996. 
BENGOA, J., 1990. Entrevista a José Bengoa C. Director de la Comisión Especial de Pueblos Indigenas. Nütram, Año VI, $\mathrm{N}^{\circ}$ 2: pp. 47-55, Santiago.

1995. Los indígenas y el Estado Nacional en América Latina. Revista de Antropología, Vol. 38, N²: pp. 151-186, Sao Paulo.

--- 1997. Los derechos de los pueblos indígenas. Liwen $\mathrm{N}^{\circ} 4$ : pp. 193-215. Temuco.

----1999a. Historia de un conflicto. El estado y los mapuches en el siglo XX, Ed. Planeta, Santiago.

-.--1999b. Una historia inconclusa (Entrevista de Daniel Swinburn), en: Artes y Letras, El Mercurio, 1 de noviembre de 1999, pp. E/6-7, Santiago.

---- 2000. La emergencia indígena en América Latina, FCE, Santiago.

BENJAMIN, W. ca. 1942. Sobre el concepto de historia, en: Idem. La dialéctica en suspenso, pp. 45-68. Arcis-Lom, Santiago.

BERNSTEIN, R. , 1996. Habermas on Law and Democracy: Critical Exchanges: Laws, Morals, and Ethics: The retrieval of the democratic ethos", en: Cardozo Law Review, pp. $1127-$ 1146, Marzo de 1996

BOLETIN, 1956. Absolución de araucana homicida por brujería. Boletín Indigenista, Vol. 15, $\mathrm{N}^{\circ}$ 2B, pp. 160-168. México.

BONFIL BATALLA, G., 1985. Indigenismo, en: Bobbio, Norberto y Matteuci, Nicola, Diccionario de Política, Tomo I, 4ta edición, Editorial Siglo XXI, pp. 837-839, Madrid.

---- 1987. México profundo. Una civilización negada, Grijalbo, México.

----- 1989. El patrimonio cultural mexicano: Un laberinto de significados. En Pensar nuestra cultura, pp. 125-145, Alianza Editorial, México, 1991.

-2-1991. Las culturas indias como proyecto civilizatorio. Pensar nuestra cultura, pp. 71-87, Alianza Editorial, México.

BOVERO, M., 1988. Por una filosofía política realista (Entrevista), en: Consino, César y Alarcón Olguín, Víctor, La filosofia política de fin de siglo, pp. 57-78, UIA-Triana Editores, México, 1994.

CERRONI, U., 1969. La crítica de Marx a la filosofía hegeliana del derecho público. Cerroni, U. Marx, el derecho y el Estado, pp. 17-48, Oikos-Tau, Barcelona.

COLLETI, L., 1969. Rousseau, crítico de la 'sociedad civil' . En: Ideología y sociedad, Universidad Central de Venezuela, pp. 197-262, Caracas, 1974.

CONNOR, W., 1994. Ethnonationalism, Princeton University Press, Princeton, New Jersey. Corresponde a trabajos publicados entre 1967 y 1993.
CRISTI, R., 1992. Estado nacional y pensamiento conservador en la obra madura de Mario Góngora. En Cristi, Renato y Ruiz, Carlos, El pensamiento conservador en Chile, pp. 140-157, Editorial Universitaria, Santiago,

----2000 El pensamiento político de Jaime Guzmán. Autoridad y Libertad, Lom Ediciones, Santiago.

CHIHUAILAF, E.,1999. Recado confidencial a los chilenos, Lom Ediciones, Santiago.

DEL VAL, J. M., 1993. El indigenismo, en: Arizpe, Lourdes (Comp.) Antropología breve de México, pp. 245-264. Academia de la Investigación Científica, México.

EYZAGUIRRE, J., 1948. Fisonomía histórica de Chile, Editorial Universitaria, Santiago, 3a edición 1973.

---- 1967. Historia de las institituciones políticas de Chile, Editorial Universitaria, Santiago, 2da edición 1977.

FETSCHER, I., 1983. Rousseau, Voltaire und wir. En Arbeit und Spiel, pp. 125-145, Reclam Verlag, Sttutgart.

FOERSTER, R, 1999. ¿Movimiento étnico o etnonacional mapuche?, Revista de Crítica Cultural 18: 52-58, Santiago.

FOERSTER, R. Y LAVANCHY, J., 1999. La problemática mapuche. En Análisis del Año 1999, Departamento de Sociología, Universidad de Chile, Santiago, págs. 65-102.

FOERSTER, R. y MONTECINO, S., 1988. Organizaciones, $l i$ deres y contiendas mapuches (1900-1970), CEM, Santiago,

FOERSTER, R. y VERGARA, J. I., 2000. Los mapuches y la lucha por el reconocimiento en la sociedad chilena. XII Congreso Internacional. Derecho consuetudinario y pluralismo legal: desafios en el tercer milenio (2 Tomos), Tomo I, Universidad de Chile-Universidad de Tarapacá, sin ciudad, sin fecha, pp. 191-206.

FREI, E., 1999a. Discurso del Presidente Eduardo Frei en Ceremonia Efectuada el 5 de Agosto de 1999 en el Palacio de la Moneda ante los Representantes Mapuches, Fundación Rehue, www.xs4all.nl/ $\sim$ rehue/act/act 198

FREI, E., 1999b. Mensaje del Presidente Eduardo Frei Ruiz-Tagle en la Firma del Pacto por el Respeto Ciudadano, MIDEPLAN. 5-8-1999.

FUKUYAMA, F., 1992. El fin de la Historia y el último hombre, Planeta, Buenos Aires.

GADAMER, H. G., 1960. Verdad y Método, Ediciones Sígueme, Salamanca, 1977.

GARCIA, J. F., 1999. Espacio público, sentido común y conflicto político en Chile. Revista de la Academia 4. otoño, Universidad Academia de Humanismo Cristiano, Santiago, págs. 35-46.

GONGORA, M., 1981. Ensayo histórico sobre la noción de Estado en Chile en los siglos XIX y XX, Editorial Universitaria, Santiago, 1986. 
GONZALEZ, S., 1999. De la solidaridad a la xenofobia: Tarapacá-Chile, 1907-1911, en: Estudios Sociológicos, Vol. XVII, N51, Colegio de México, México, pp. 837-845.

GONZALEZ, S., 1993. et al Ligas patrióticas, en: Revista de Investigaciones Cientificas y Tecnológicas $\mathrm{N}^{\circ} 2$, Universidad Arturo Prat, Iquique, pp. 37-49.

GUNDERMANN, H., 1995. Comunidad indígena y ciudadanía. La experiencia aymara en el norte de Chile, en: Allpanchis, Año XXVII, Na46, Cusco, Perú, pp. 91-130.

---- 1997. Etnicidad, identidad étnica y ciudadanía en los países andinos y en el norte de Chile, en: Estudios Atacameños $\mathrm{N}^{\circ} 13$, San Pedro de Atacama, pp. 9-26.

---- 1998. Comunidad aymara, identidades colectivas y estados nacionales, en: Artaza Barrios, Pablo et al, A 90 años de los sucesos de la Escuela Santa María de Iquique, Lom Ediciones-DIBAM, Santiago, pp. 153-181.

HABERMAS, J., 1965. "Erkenntnis und Interesse", en: Idem, Technik und Wissenschaft als Ideologie, Suhrkamp, Francfort del Meno, 1967, pp. 146-167.

----1968. Erkenntnis und Interesse, Suhrkamp, Francfort del Meno, 1994.

----- 1984. Conocimiento e interés, en: Idem, Ciencia y técnica como ideología, Ed. Tecnos, Madrid, pp. 159-181. Traducción de Habermas (1965).

-.--1987. Die Schrecken der Autonomie. Carl Schmitt auf Englisch, en: Idem, Eine Art Schadensabwicklung (Kleine Politische Schriften VI), Suhrkamp, Francfort, pp. 101-113.

..-- 1988a. Los usos pragmáticos, éticos y morales de la razón práctica, en: Idem, Moralidad y política, Alianza Editorial, México, 1993, pp. 59-78.

..... 1988b. Ser resueltamente modernos, en: Revista de la Universidad del Valle $\mathrm{N}^{\mathrm{o}} 6$, noviembre de 1993, pp. 38-43. Original, en: Autrement $\mathrm{N}^{\circ} 102$, París, pp. 23-29.

---- 1989. Carl Schmitt: Los terrores de la autonomía. Identidades nacionales y postnacionales, Tecnos, Madrid, 1989, págs. 67-82. Traducción de Habermas (1987).

---1990. Conocimiento e interés, Taurus, Madrid. Traducción de Habermas (1968).

----- 1992. Ciudadanía e identidad nacional. Consideraciones sobre el futuro europeo, en: Debats $\mathrm{N}^{\circ} 39$, Valencia, 1992, pp. 11-18.

----1996a. The European Nation-state- Its Achievements and Its Limits. On the Past and Future of Sovereignity and Citizenship, en: Balakrishan, Copal (Editor) Mapping the Nation, Verso, London, $1^{2}$ reimpresión 1999, pp. 281-294.

---- 1996b. Die Einbeziehung des Anderen, Suhrkamp, Francfort del Meno, 1997.

---1996c. Entrevista con Barbara Freitag y Sergio Paulo Rouanet, en: Diálogo Científico, Vol. 5, Nos. 1-2, Tübingen, pp. 161-188.

--.- 1998. Was ist ein Volk? Zum politischen Selbstvertändnis der Geistwissenschaften im Vormärz, am Beispiel der Frankfurter Germannistenversammlung von 1846, en: Idem, Die postnationalle Konstellation, Suhrkamp, Francfort del Meno, pp. 18-26.

---- 1999. La inclusión del otro, Paidós, Barcelona. Traducción de: Habermas (1996b, capítulos 1 y 4-10).

----2000. ¿Qué es un pueblo. Sobre la autocomprensión política de las ciencias humanas en el 'Vormärz'. El ejemplo de la Asamblea de Germanistas celebrada en Francfort en 1846, en: Idem, La constelación post-nacional, Paidós, Barcelona, pp. 15-42. Traducción de Habermas (1998).

HINKELAMMERT, F., 1987a. El estado de seguridad nacional, su democratización y la democracia liberal en América Latina, en: Idem, Democracia y totalitarismo, Amerinda, Santiago, pp. 211-228.

----1987b. El concepto de lo político según Carl Schmitt, en: Idem, Democracia y totalitarismo, Amerindia, Santiago, pp. 113-131.

HONNETH, A., 1989. Moralische Entwicklung und sozialer Kampf, en: Honneth, Axel et al (Editores), Zwischenbetrachtungen im Prozess der Aufklärung, Suhrkamp, Francfort del Meno, pp. 549-573.

----- 1992. Kampf um Annerkenung. Zur moralischen Grammatik sozialer Konflikte, Suhrkamp, Francfort del Meno, 1994.

HROCH, M., 1993. From national movement to the fullyformed nation: the nation-building process in Europe, en: Balakrishan, Copal (Editor) Mapping the Nation, Verso, London, $1^{2}$ reimpresión 1999, pp. 78-97.

Jurisprudencia, 1956. La absolución de la mujer araucana homicida por brujería es formulada como doctrina jurídica, en: Revista Chilena de Derecho y Jurisprudencia, Tomo III, $\mathrm{N}^{\circ} \mathrm{s}$ 5-6, Segunda parte, Sección Cuarta, pp. 85-102.

KMYLICKA, W., 1996. Ciudadanía multicultural, Paidós, Barcelona.

KOSELLECK, R., 1959. Kritik und Krise, Suhrkamp, Francfort, 1973.

KOSELLECK, R, 1965. Crítica y crisis del mundo burgués, Ediciones Rialp, Madrid. Traducción de la obra anterior.

KOTOV, R. y VERGARA, J. I., 1997. La identidad mapuche en la perspectiva de los intelectuales indígenas, en: Actas. Segundo Congreso Chileno de Antropología (Valdivia, 1995), Colegio de Antropólogos de Chile, Santiago, Tomo I, pp. 452-461.

LAVANCHY, J., 1999a. Perspectivas para la comprensión del conflicto mapuche, Santiago, septiembre de 1999, en: Fundación Rehue, http://www.xs4all.nl/ rehue/art/lava2.html.

----1999b. Conflicto y propuestas de autonomía mapuche, Santiago, junio de 1999, en: Fundación Rehue, http:// 
www.xs4all.nl/ rehue/ar t/lava1.html.

LECHNER, N., 1980. La teoría y la práctica de la política, en: Estudios Sociales Centroamericanos, Año IX, No25, San José, Costa Rica, 1980, pp. 207-263.

---- 1984. La conflictiva y nunca acabada construcción del orden deseado, Flacso, Santiago, 1984.

--1985. De la revolución a la democracia, en: Idem. Los patios interiores de la democracia. Flacso, Santiago, 1988, pp. $21-43$.

...-- 1991. Repensar el Estado democrático, en: Tagle, Matías (Editor) Desafíos del Estado en los años 90, Corporación de Promoción Universitaria, Santiago, pp. 57-59.

---- 1997. Tres formas de coordinación social, en: Revista de la Cepal No61, Santiago, pp. 7-17.

LILLA, MARK, 1997. The enemy of liberalism, en: The New York Review of Books $\mathrm{N}^{\circ} 8,15$ de mayo de 1997, Nueva York, pp. 38-44.

LOCKE, J., 1690. Ensayo sobre el Gobierno Civil, Aguilar Ediciones, Madrid, 1990. Original: Two Treatises of government, Cambridge, 1960.

MACCARTHY, T., 1989. Philosophy and social practice: avoiding the ethnocentric predicament, en: Honneth, Axel et al (Editores), Zwischenbetrachtungen im Prozess der Aufklärung, Suhrkamp, Francfort del Meno, pp. 190-209.

MAC FALL, S., 1998. Keeping identity in its place. Culture and politics among the mapuche of Chile, Tesis de doctorado, St Cross College, Oxford University, Ms.

MACPHERSON, C. B., 1962. La teoria política del individualismo posesivo, Editorial Fontanella, Barcelona, 2da edición 1979.

---- 1976. La democracia liberal y su época, Alianza Editorial, Madrid, 1982.

MALLON, F., 1999. Cuando la amnesia se impone con sangre, el abuso se hace costumbre: el pueblo mapuche y el Estado chileno, 1881-1998, en: Drake, Paul W. y Jaksic, Iván (Editores) El modelo chileno. Democracia y desarrollo en los noventa, Lom Ediciones, Santiago, pp. 435-464.

MARCUSE, H., 1964. The One-Dimensional Man. Studies in the ideology of advanced industrial society, Beacon Press, Boston.

-.--- 1965. El hombre unidimensional, Seix Barral, Barcelona. Traducción del trabajo anterior.

---- 1966. El individuo en Ja 'Gran Sociedad', en: Idem: La sociedad opresora, Editorial Tiempo Nuevo, Caracas, 2da edición 1972, pp. 133-162. Hay otra traducción en: Marcuse, Herbert, Ensayos sobre política y cultura, Ariel, Barcelona, 1970, pp. 41-86.

MARIMAN, J., 1998. Lumaco y el movimiento mapuche, Denver, 1998, en: Fundación Rehue, http://www.xs4all.nl/ -rehue/art/jmar6.html.

MEIER, H., 1994. Die Lehre Carl Schmitts: Vier Kapitel zur Unterscheidung Politischer Theologie und Politischer Philosophie, Metzler Verlag, Stuttgart.

MEINECKE, F., 1936. El historicismo y su génesis, FCE, México, 1943.

NAGUIL, V., 1999. Conflictos en el territorio mapuche. Intereses, derechos y soluciones políticas en juego, en: Liwen $\mathrm{N}^{\circ}$ 5, Temuco, pp. 11-41.

NAMUNCURA, D., 1999. Ralco: ¿represa o pobreza?, Lom Ediciones, Santiago.

QUINTANA, G., 1999. Diálogo con el Pueblo Mapuche: Puentes y no Muros, en: La Revista de Mideplan, Año 1, $\mathrm{N}^{\circ} 2$, septiembre 1999, MIDEPLAN, Santiago, pp. 25-26.

ROUSSEAU, J. J., 1754. Discurso sobre el origen de la desigualdad entre los hombres, en: Idem, Del contrato social/ Discurso sobre las ciencias y las artes/Discurso sobre el origen de la desigualdad entre los hombres, Alianza Editorial, Madrid, 1980, pp. 177-287.

SCHMITT, C., 1928. Verfassungslehre, Duncker \& Humblot, Berlón, $8^{\text {a }}$ edición 1993 Traducción al español: Teoría de la Constitución, Alianza Editorial, Madrid, 1982.

---- 1932. Der Begriff des Politischen, Duncker \& Humblot, Berlín, 6da edición 1996.

-- 1984. El concepto de 'lo político', Folios, México. Traduc ción de Schmitt (1932).

SKEWES, J. C., 1999. La muerte de la bruja, la supervivencia de un pueblo y el pluralismo legal, en: Austerra $\mathrm{N}^{\circ} 1$, Universidad Bolivariana. Santiago, pp. 91-92.

SMITH, A., 1997. La identidad nacional, Trama Editorial, Madrid.

STUCHLIK, M., 1974. Rasgos fundamentales de la sociedad mapuche contemporánea, Ediciones Nueva Universidad, Santiago.

---- 1985. Las políticas indígenas en Chile y la imagen de los mapuches, en: Cultura-Hombre-Sociedad (CUHSO), Vol. 2 , $\mathrm{N}^{\circ} 2$, Temuco, Universidad Católica de Temuco, pp. 159-194.

TAYLOR, CH., 1985. La ciencia social como práctica, en: Revista de la Academia $\mathrm{N}^{\circ} 3$, Universidad Academia de $\mathrm{Hu}-$ manismo Cristiano, Santiago, 1998, pp. 165-188. Traducción del capítulo 3 de: Philosophy and Social Sciences, Cambridge University Press, Cambridge.

1992 ¿Qué principio de identidad colectiva?, en: La Política $\mathrm{N}^{\circ} 3$, octubre de 1997, Barcelona-Buenos Aires, pp. 133 137. Publicado originalmente en: Lenoble, Jacques y Dewandre, Nicole (Editores) L' Europe au soir du siécle, Edicions Esprit. París.

-- 1993. La política del reconocimiento, en: Taylor, Charles et al, El multiculturalismo y la política del reconocimiento, 
FCE, México, pp. 43-107.

-..-1 1994. Los problemas de la sociedad multicultural. Entrevista por María Elósegui, en: Debats $\mathrm{N}^{\circ}$ 47, Valencia, pp. 4146.

TOURAINE, A., 1997. ¿Podremos vivir juntos?, FCE, Buenos Aires.

VERGARA, J. I., 1998. La frontera étnica del Leviatán, Tesis de Doctorado en Sociología, Universidad Libre de Berlín, Ms.

-_-2000. La cuestión nacional y el rol del Estado en los procesos de integración étnica en el debate latinoamericano y chileno, en: Revista de la Academia N$^{\circ}$ 5, Otoño 2000, Universidad Academia de Humanismo Cristiano, Santiago, pp. 127168.

VERGARA, J. I., 1999, et al Las tierras de la ira. Los sucesos de Traiguén y los conflictos entre comunidades mapuches, empresas forestales y Estado, en: Praxis. Revista de Psicología y Ciencias Humanas, Universidad Diego Portales, Santiago, pp. 112-128.

VERGARA E. J., 1989. El paradigma liberal democrático, en: Sociológica $\mathrm{N}^{\circ} 7 / 8$, UAM, México, pp. 15-44.
-.--1990. Acción comunicativa y democracia en Habermas, en: Cuadernos del Cendes N's 13-14, Caracas, pp. 268-282.

---- 1995. Concepciones de justicia en el liberalismo, en: Decursos, Año 1, Nº1, USM, Cochabamba, 1995, pp. 5-23.

---- 1997. El tema de la igualdad en el liberalismo contemporáneo, en: Anuario de Filosofía Jurídica y Social $\mathrm{N}^{\circ} 15$, Sociedad Chilena de Filosofía Jurídica y Social, Valparaíso, pp. 63-86.

WALZER, M., 1989. El liberalismo y el arte de la separación en Opciones $N^{\circ}$ 6, CERC, Santiago, pp. 19-44 (publicado en inglés en 1984).

---- 1993. Comentario, en: Taylor, Charles, El multiculturalismo y la política del reconocimiento, FCE, México, pp. 139-145.

----1 1996. Zivile Gesellschaft und amerikanische Demokratie, Fischer, Francfort del Meno.

WEBER, M., 1919. Politik als Beruf, Philipp Reclam, Stuttgart, 1992. Traducción al español: La política como vocación (1919), en: Idem, El político y el científico, Alianza Editorial, Madrid, 1969; también en: Idem, Escritos políticos (1958), Tomo II, Ediciones Folios, México, 1982, pp. 308-364. 